TITLE:

\title{
Evaluation of modelling approaches for machine tool design
}

AUTHOR(S):

Kono, Daisuke; Lorenzer, Thomas; Weikert, Sascha; Wegener, Konrad

\section{CITATION:}

Kono, Daisuke ... [et al]. Evaluation of modelling approaches for machine tool design. Precision Engineering 2010, 34(3): 399-407

ISSUE DATE:

2010-07

URL:

http://hdl.handle.net/2433/113885

\section{RIGHT:}

C 2010 Elsevier B.V.; この論文は出版社版でありません。引用の際には 出版社版をご確認ご利用ください。; This is not the published version. Please cite only the published version. 


\title{
Evaluation of Modelling Approaches for Machine Tool Design
}

\author{
Daisuke Kono $^{1}$, Thomas Lorenzer $^{2}$, Sascha Weikert ${ }^{3}$, Konrad Wegener ${ }^{3}$ \\ ${ }^{1}$ Dept. of Micro Engineering, Graduate School of Engineering, Kyoto University \\ Yoshida-honmachi, Sakyo-ku, Kyoto 606-8501, Japan \\ Email: Daisuke.Kono@t02.mbox.media.kyoto-u.ac.jp \\ Phone: $+81-75-753-5226$ \\ Fax: $+81-75-753-5226$ \\ 2 Inspire AG \\ Tannenstrasse 3, 8092, Zurich, Switzerland \\ ${ }^{3}$ Institute for Machine Tools and Manufacturing (IWF), ETH Zurich \\ Tannenstrasse 3, 8092, Zurich, Switzerland
}

\begin{abstract}
:
In order to evaluate the configuration of machine tools, the IWF Axis Construction Kit (ACK) has been developed. This paper describes the evaluation of this approach. The ACK supports rigid body simulations and simple elastic body simulations. The ACK is compared with commercial FEM software to investigate its usability and reliability. Required time was compared in modelling of a machine tool. The ACK needed $30 \%$ of the total required time for the FEM because of its modularity in machine modelling. Then, in order to investigate the reliability of the ACK, static and dynamic simulations of both approaches were compared with each other and with analytical calculations on basic beam models. The result showed that the ACK provided equivalent results to the FEM. Static and dynamic simulations were also compared with measurements on an actual machine tool. The ACK obtained almost equivalent results to the FEM. Almost all lower structural mode shapes and their natural frequencies could be reproduced with the ACK when crucial parts were modelled using elastic bodies.
\end{abstract}

Keywords: rigid body simulation, finite element method, modal analysis, machine tool design 


\section{Introduction}

Recently, dynamic errors of machine tools such as vibration are one of the crucial problems in high precision machining. Since dynamic properties of machines are greatly influenced by the machine configuration, the configuration should be evaluated very early in the design phase. However, only few manufacturers use evaluation tools in order to check configuration variants. For this reason, a lack of reliable and effortless simulation software can be stated. Simulation methods for machine tools can roughly be classified into two groups: one is the finite element method (FEM) and the other is the rigid multi-body simulation (MBS) [1].

In industrial use, the FEM is popular and widely used. Several studies have been carried out, modelling machine components with the FEM. Zaeh and Oertli have developed a model for ball screw drives by the cross coupling between axial and torsional degrees of freedom [2]. Altintas and Cao have developed a FEM model of spindles composed of nonlinear models of shafts and bearings [3][4]. Reliable results can be obtained with the FEM. Furthermore, the FEM is useful in the design process because many FEM software packages have useful interfaces to 3D CAD systems.

However, the FEM needs much calculation effort to model the whole structure of a machine because of its large number of degrees of freedom (nDOF). In commercial software, coupling settings between assembled parts are often not practical to represent guideways or ballscrews, and detailed modelling in a certain level is required to avoid the interference between components. In order to reduce $\mathrm{nDOF}$, the machine has been divided into subcomponents or modules, and these modules have been coupled with boundary conditions [5-8]. Also in the simulations of positioning system with flexture hinges, hinges are modelled as a simple beam element to reduce $\mathrm{nDOF}[9]$. 
Compared to the FEM, nDOF can be significantly reduced when using the MBS. Especially in the early design stage, the MBS is an appropriate tool to obtain quick and rough predictions of the machine behaviour [1]. Teeuwsen et al. developed a motion error model of CMM with the MBS [10]. Tool motions in the time domain and modal characteristics have been simulated by the MBS also for machine tools [11][12]. In recent years, the MBS has been used for real time simulation of motion errors [13]. The MBS and the FEM were combined to acquire more reliable results in dynamic analyses [14]. Although these studies have shown the advantage of the MBS, there are only few practical software packages that focus on the construction of machine tools.

As can be seen in the use of the FEM, a combination of 3D CAD and commercial MBS software is used to analyse the motion of a parallel kinematic machine tool [15]. This method is practical. However, commercial software packages generally need more effort to model a specific machine, since they are designed for all-purpose.

In order to evaluate the configuration of machine tools, the Axis Construction Kit (ACK) has been developed at the IWF (ETH Zurich, Institute for Machine Tools and Manufacturing)[16]. Fundamental machine properties can be obtained in a very short time by a simple model composed of masses and springs. The model is easily constructed using modules of mechanical components. The ACK can handle not only the MBS but also simple elastic body simulations. Static and dynamic analyses can be conducted.

In this paper, the ACK is compared with commercial FEM software to evaluate its reliability and usability. First, required time for modelling of a machine tool is compared. Then, simple beams are modelled with both approaches. The obtained results are compared with each other and with analytical calculations to investigate the 
reliability of elastic body simulations of the ACK. Finally, an existing machine is modelled, and static and dynamic behaviours are compared with measurements on the real machine. The effect of elastic body simulations is also evaluated.

\section{Modelling of a three axis machine tool}

\subsection{Simulation object}

A high precision machine tool is modelled with the ACK and the FEM. Figure 1 shows the machine under investigation. The machine has been developed for shaping / grooving in the XY plane by a single-diamond tool. It is mounted on a vibration isolation table to avoid vibration in the Z-direction. This machine has three linear axes. Precision ball screws and servo motors are employed in each drive system. The X-axis uses aerostatic guideways. The Y- and Z-axes employ linear ball guideways. The major specifications of the machine and the vibration isolation table are shown in Table 1.

\subsection{Modelling with the Axis Construction Kit}

Figure 2 shows the simulation model developed with the ACK. The machine parts are simplified into rigid rectangle bodies. Some parts are grouped in one component, and the seven components shown in Fig.2 compose the model consequently. The components are coupled with discrete springs in X-, Y- and Z-directions. Sliders and bases are connected with couplings, which represent guideways and drives. The machine base is coupled to an inertial system with weak springs at the corners representing air springs of the vibration isolation table. The machine base, the columns, and the Y-base are rigidly coupled with stiff springs which represent bolts or screws.

The ACK can handle elastic body simulations using segmented bodies coupled with each other. In this paper, five different models are developed to investigate the effect of 
different elastic body representations. Figure 3 shows the schematic of these five models. The details of the models are as follows;

Rigid (R): This is the basic model. All bodies are rigid. The machine base, the columns, and the Y-base are rigidly coupled. (The model is described in the first paragraph.)

Bolts elastic (BE): The machine base and the columns are elastically coupled.

Columns elastic (CE): The columns are elastic and segmented in the Z-direction.

Y-base elastic (YE): The Y-base is elastic and segmented in the Y-direction.

Y-base and columns elastic (YCE): The Y-base as well as the columns is elastic.

The initial model parameters are identified in the following procedure: the dimensions of bodies are determined from their outward forms, and the densities are adjusted so that the masses agree to the design value. The stiffness of the guideways of Y- and Z-axes are derived from their catalogue specifications. The stiffness of air springs, drives and the X-guideway are identified experimentally.

In order to confirm the reliability of the approach when parameters are properly selected, these parameters are tuned using the result of the experimental modal analysis described in section 4.2. The modified parameters are the stiffness in the Z-direction of the Y-guideway, the stiffness of the Y-drive and the thickness of the columns and the Y-base. In BE, the stiffness in the Z-direction of the couplings between the machine base and the columns is determined also from the result of the modal analysis. Because this paper focuses on static displacements and natural frequencies with mode shapes, damping has not to been taken into account. 


\subsection{Modelling with commercial FEM software}

The machine is also modelled with a commercial FEM software package, Ansys Workbench, similarly as mentioned in Section 2.2. Bonded contacts are used to group the bodies. The rigidity or the elasticity of bodies is determined by the behaviour of surface nodes. Bodies are meshed automatically under default settings. With the FEM, reference surfaces are required to couple components. However, the reference surfaces affect the behaviour of elastic bodies. In order to suppress this influence, reference surfaces are minimised using the extrusion with the thickness of $1 \mu \mathrm{m}$ so that only actual contacted areas become the reference.

\subsection{Comparison in required time for the ACK and a commercial FEM}

The time required for simulations with the ACK and the FEM is compared. The evaluation is carried out in modelling, modal analysis and the modification of the thickness of the columns after the analysis on R. The operator has all the model parameters at hand and has developed the same model several times with both software. With the FEM, modelling of the extrusion for the reference surface is omitted to investigate the time in the equivalent operations to ACK.

The comparison of the required time is shown in Fig.4. It is observed that the ACK needs only $30 \%$ of the total required time for the FEM. Direct 3D modelling and module coupling system mainly contribute to this time reduction. Comparing the time required for the modification, the ACK needs $25 \%$ of for time with the FEM.

\section{Fundamental evaluation on basic components}

In order to evaluate the accuracy of elastic body simulations by the ACK, simulation results are compared with those by the FEM and with analytical calculations in basic simulations. In elastic body simulations, the number of degrees of freedom (nDOF) of 
models has a large influence. Therefore, simulations are conducted with various $\mathrm{nDOF}$ to clarify this effect. The simulation of displacements due to static forces and the modal analysis are carried out on a cantilever and a beam fixed on both sides. In this paper, nDOF with the ACK and the FEM are calculated as follows:

$$
\begin{aligned}
& n D O F_{A C K}=6 \times m_{e} \\
& n D O F_{F E M}=3 \times m_{n}
\end{aligned}
$$

where $m_{e}$ is the number of elements(segmented bodies) and $m_{n}$ is the number of nodes. For example with the FEM, nDOF of a single element is 60 with a 20 -node solid element composed of 8 corner and 12 midside nodes. When elements are connected, nDOF of nodes shared on boundaries decreases.

\subsection{Cantilever beam}

Figure 5 shows a cantilever used in the calculation. $l, h$ and $t$ represent the width, the height and the thickness of the cantilever, respectively. In static analyses, forces are applied at the load point, which is on the center of the top surface. The cantilever is segmented in the Z-direction with the ACK. In order to compare the ACK and the FEM in the similar nDOF, the cantilever is modelled without midside nodes with the FEM. The physical parameters are determined according to those of steel. Derived from the dimension of the the columns of the machine, the dimensions, $l=100 \mathrm{~mm}, h=500 \mathrm{~mm}$ and $t=38 \mathrm{~mm}$, are used in the simulations.

\subsubsection{Displacement due to static forces}

The translational forces in three directions, $F_{x}, F_{y}$ and $F_{z}$, and moments, $M_{a}, M_{b}$ and $M_{c}$, are applied at the load point one by one. The displacements due to $M_{a}, M_{b}$ and $M_{c}$ are evaluated in $\mathrm{X}$ - and $\mathrm{Y}$-directions at the load point. The displacement due to 
$M_{c}$ is calculated as the product of a distance of $l / 2$ and an angle of twist at the top surface. In this calculation, the translational force of $1 \mathrm{kN}$ and the moment of $1 \mathrm{Nm}$ are loaded.

The deviation of the static displacement calculated by the ACK and the FEM from its analytical value is shown in Figs.6 and 7, respectively. In Fig.6, it can be observed that deviations on the displacement due to $F_{x}$ and $F_{y}\left(d x\left(F_{x}\right)\right.$ and $\left.d y\left(F_{y}\right)\right)$ decrease while nDOF increases from 12 to 60 . With nDOF more than 60 , the deviations are almost constant. This result shows that nDOF must be 30 , which corresponds to 5elements with the ACK or larger, to obtain the deviation smaller than $10 \%$. The deviations are smaller than $4 \%$ when nDOF is more than 90 .

In Fig.7, the deviation on $d x\left(M_{c}\right)$ is still larger than $10 \%$ even when $\mathrm{nDOF}$ is more than 500. This deviation is caused by the lack of mideside nodes. As for other displacements, $\mathrm{nDOF}$ must be more than 40 to reduce the deviation to $10 \%$ for the FEM. The deviations are smaller than $2 \%$ with nDOF more than 200. Comparing Figs. 6 and 7, the difference in deviations is smaller than $5 \%$ between both approaches with nDOF more than 100. This result shows that the ACK has an equivalent accuracy to the FEM. Furthermore, the ACK typically calculates displacements larger than the FEM when $\mathrm{nDOF}$ is smaller, which can be seen as a conservative manner of evaluating machine design.

\subsubsection{Modal analysis for the cantilever}

The natural frequencies of the first six modes are calculated. The first six modes of this cantilever are the first bending mode in the X-direction, the first bending mode in the $\mathrm{Y}$-direction, the second bending mode in the $\mathrm{X}$-direction, the first torsion mode, the second bending mode in the Y-direction and the third bending mode in the X-direction. 
The deviations of natural frequencies calculated by the ACK and the FEM from their analytical values are shown in Figs. 8 and 9, respectively. In both computations, the third bending mode in the X-direction was not observed with the smallest nDOF. With the ACK, nDOF must be larger than 60 , which corresponds to 10 elements, to reduce the deviation to $20 \%$. The deviations are smaller than $16 \%$ with nDOF more than 200 .

In Fig.9, nDOF must be larger than 100 for the FEM to obtain the deviation smaller than $20 \%$. The deviations are smaller than $15 \%$ with nDOF more than 200 . Comparing Figs.8 and 9, the deviations with the ACK are smaller in the second and third modes in the X-direction with nDOF from 40 to 100 . The difference of deviations is smaller than $10 \%$ between both approaches when nDOF is more than 100 .

\subsection{Fixed beam}

Figure 10 shows a beam fixed on both sides to be used for comparison. In Fig.10, $h_{F}$ represents the distance in the Z-direction from the center of the front surface to the load point. The beam is segmented in the Y-direction with the ACK. In the modal analysis, the beam is modelled without midside nodes with the FEM. In the static analysis with the FEM, a small plate with the size of $0.5 \mathrm{~mm} \times 10 \mathrm{~mm} \times 10 \mathrm{~mm}(\mathrm{X} \times \mathrm{Y} \times \mathrm{Z})$ is extruded at the load point as the reference surface of the load. The beam is not meshed uniformly because of this plate. Since midside nodes could have a large influence in such a case, the beam is modelled with and without midside nodes in the static analysis. The physical parameters are determined according to those of steel. Derived from the dimension of the Y-base of the machine, the dimensions, $l=750 \mathrm{~mm}, h=250 \mathrm{~mm}$ and $t=32 \mathrm{~mm}$, are used in the simulation. However, the simulation results shall deviate from analytical Euler-Bernoulli solutions because of a small ratio of $l / h$ and $l / t$.

\subsubsection{Displacement due to static forces}


When the translational force in the $\mathrm{X}$-direction, $F_{x}$, is applied at the load point, the displacements in X-and Z-directions at the load point, $d x\left(F_{x}\right)$ and $d z\left(F_{x}\right)$, are calculated. $d x\left(F_{x}\right)$ is computed as the sum of translational and angular displacements. $F_{x}=1 \mathrm{kN}$ is loaded at $h_{F}=0 \mathrm{~mm}$ and $h_{F}=100 \mathrm{~mm}$ in the calculation.

The deviations of static displacements calculated with the ACK and the FEM from the analytical displacements are shown in Figs. 11 and 12, respectively. In Fig.11, it can be observed that the deviations on $d x\left(F_{x}\right)$ decrease while $\mathrm{nDOF}$ increases from 18 to 200. With nDOF more than 200 , the deviations are almost constant. nDOF must be larger than 90 , which corresponds to 15 elements, to reduce the deviation to $10 \%$ with the ACK. The deviations on $d x\left(F_{x}\right)$ and $d z\left(F_{x}\right)$ are smaller than $3 \%$ with nDOF more than 300 .

In Fig. 12, deviations are larger than $70 \%$ when midside nodes are not used. In the result with midside nodes, these deviations are reduced to $12-40 \%$. Deviations at $h_{F}=100 \mathrm{~mm}$ are still larger than $10 \%$ even when $\mathrm{nDOF}$ is about $10^{4}$. Comparing the $\mathrm{ACK}$ and the FEM, it can be observed that the ACK requires about $1 / 30$ of $\mathrm{nDOF}$ to have the same accuracy as the FEM.

\subsubsection{Modal analysis for the fixed beam}

The natural frequencies of the first three modes of the beam shown in Fig.10 are calculated. The first three modes of the fixed beam are the first bending mode in the Xdirection, the first torsion mode and the second bending mode in the X-direction.

The deviations of the natural frequencies calculated by the ACK and the FEM from analytical frequencies are shown in Figs. 13 and 14, respectively. In Fig.13, nDOF must 
be larger than 60 for the ACK to reduce the deviation to $20 \%$. The deviations are smaller than $3 \%$ when $\mathrm{nDOF}$ is more than 400 .

In Fig. 14, the deviation is still larger than $20 \%$ for the torsion mode even when nDOF is more than $10^{3}$. Other two deviations are smaller than $20 \%$ when nDOF is 210 , and smaller than $3 \%$ when $\mathrm{nDOF}$ is more than 800 . Comparing the ACK and the FEM, it can be observed that the ACK requires about half of $\mathrm{nDOF}$ to have the same accuracy as the FEM.

\section{Evaluation on a real machine}

Static and dynamic behaviours are simulated on the machine tool under investigation. In static and dynamic simulations in the frequency domain, simulation results with the ACK and the FEM are compared with experimental results to evaluate their accuracy. In these simulations, five different models are compared to investigate the effect of the elastic body simulation. Then, the dynamic simulation with the ACK in the time domain is demonstrated. The machine and its models were described in Chapter 2.

\subsection{Static compliance at TCP}

For a static evaluation, the compliances relative to the machine base in the Zdirection against forces in X-, Y-and Z-directions $\left(F_{x}, F_{y}\right.$ and $\left.F_{z}\right)$ are evaluated at the tool center point (TCP). In the experiment, a tool post and a laser displacement sensor (Keyence, LK-G08) are fixed on the Z-slider, and an optical flat is fixed on the X-slider as shown in Fig.15. The Y-axis is offset by $30 \mathrm{~mm}$ from the center of the X-slider. Forces are loaded at the corner of the tool post, and are measured by using a force sensor(Kistler, 9311B). The displacement between the displacement sensor and the optical flat, $d z$, is also measured to obtain the compliance in the Z-direction. The 
measurement point of the displacement sensor is regarded as TCP. The compliances are defined similarly in the simulations.

The resolution of the displacement sensor is $10 \mathrm{~nm}$. The resolution of the force sensor derived from an $\mathrm{A} / \mathrm{D}$ converter is about $6 \mathrm{mN}$. The measurements are conducted for 3 times. Considering the accuracy and the calculation effort, the columns and Y-base are modelled with 10 elements for the ACK. With the FEM, elastic components are modelled with midside nodes, and the numbers of nodes of the column $\mathrm{L}$, the column $\mathrm{R}$ and the Y-base are 561, 330 and 688, respectively.

The relationship between measured magnitude of displacement and force is shown in Fig.16. The initial value of displacement and force is set to zero. Since the displacements due to $F_{x}$ and $F_{y}$ are similar, it is difficult to distinguish them. In order to identify the compliances, a linear curvature was fitted to each result by the least squares method. The compliances against $F_{x}, F_{y}$ and $F_{z}$ were identified to $d z / F_{x}=9.3$ $\mu \mathrm{m} / \mathrm{kN}, d z / F_{y}=11.5 \mu \mathrm{m} / \mathrm{kN}$ and $d z / F_{z}=151 \mu \mathrm{m} / \mathrm{kN}$, respectively. The standard deviations of the approximation error were $0.10 \mu \mathrm{m}, 0.17 \mu \mathrm{m}$ and $0.20 \mu \mathrm{m}$.

Figures 17 and 18 show the relationship between the modelled elasticity and deviation of the ACK and the FEM from the experimental compliance, respectively. In Fig. 17, large deviations more than $50 \%$ are observed in the compliances against $F_{x}$ and $F_{y}$. The compliances against $F_{x}$ between the model variants vary by more than $100 \%$ due to the elasticity. However, the variations in other compliances are less than $50 \%$. This result shows that the influence of the elasticity depends on the directions.

In Fig.18, large deviations, more than $50 \%$, are also observed in the compliances against $F_{x}$ and $F_{y}$. Since deviations are observed in both approaches, these 
discrepancies are caused by the simplified model of the machine. Comparing the compliances against $F_{x}$ with the ACK and the FEM, about $45 \%$ difference exists with YE and YCE. Differences are smaller than $15 \%$ in other results. Considering the identification accuracy of the compliances, the ACK and the FEM provide comparable results.

\subsection{Modal analysis of the machine}

For a dynamic evaluation, a modal analysis of the machine is carried out. Natural frequencies and mode shapes obtained with the ACK and the FEM are compared to experimental results. The experimental modal analysis is conducted by impact testing using a impact hammer(PCB Piezotronics, 086C20). In order to obtain 3D mode shapes, a 3D accelerometer(PCB Piezotronics, 356A16) is used to measure the acceleration at different points on the machine. The frequency response between the excitation force and acceleration is computed with a FFT-analyzer(Ono Sokki, CF-3400). An excitation point is selected on the tool post. The number of measurement points is 48 , and the bandwidth in this experiment is $500 \mathrm{~Hz}$. The columns and the Y-base are modelled with 20 elements with the ACK. With the FEM, these bodies are modelled similarly as described in Section 4.1.

The natural frequencies and the mode shapes obtained by the experimental modal analysis are shown in Table 2 . Since lower structural modes are focussed on, rigid body modes and the modes with the natural frequencies higher than $300 \mathrm{~Hz}$ are omitted. It can be observed that modes 1 and 4 have a larger influence on the TCP in the Zdirection. Figures 19(a) and (b) show the mode shape of mode 1 and 4, respectively. In mode 1 , the deformation of the columns is dominant. On the other hand, the deformation of the Y-base is dominant in mode 4. 
Table 3 shows examples of natural frequencies calculated in simulations. Gray cells indicate that the modes that are changed from those in $\mathrm{R}$, or are absent in $\mathrm{R}$. When the mode shape is close to that obtained by the experimental analysis, its mode number and natural frequency are copied from Table 2 to the right column at each model.

Comparing the results of YCE with the ACK and that with the FEM, both natural frequencies and mode shapes agree well. It was confirmed that results were also similar on other four models with both approaches.

The model R only represents two higher mode shapes, since local modes of each component are dominant in these higher modes. As the model includes more elasticity, new modes appear, and more modes match with experimentally-obtained modes. In results of YCE with the ACK, almost all experimental mode shapes can be reproduced. The mode 5 of YCE with the ACK and the FEM contain mode shapes of modes 6 and 7 in the experiment. One of the reasons why the model can not represent mode 5 and 7 could be the influence of the rigid couplings between the machine base and the columns. In the results of $\mathrm{BE}$ and $\mathrm{CE}$, the natural frequencies of mode 3 and 4 are about $45 \%$ higher than the experimental results. This is because the elasticity of the Y-base is not considered in these models.

\subsection{Dynamic simulation of TCP in time domain}

The lateral path deviation of TCP in a straight motion is simulated with the ACK and compared with an experimental result. In this comparison, the deviation due to acceleration and deceleration are focused on to evaluate the dynamic model of the machine.

In the experiment, the relative displacement of TCP to the X-slider in the Z-direction is measured with an optical flat and the laser displacement sensor(Keyence, LK-G08) 
used in the experiment in Section 4.1 when the $\mathrm{X}$-axis is driven toward the positive direction. The X-position is also measured using a linear encoder with a resolution of 10 $\mathrm{nm}$ to detect the acceleration (and deceleration) period. The position of each axis is similar to that in the compliance measurement described in Section 4.1. The relative displacement is computed similarly with the ACK using BE. In the simulation, the structural model is connected to additional components representing drives and controls to reproduce the actuation of the machine tool [11].

The displacement is measured at a commanded feedrate of $600 \mathrm{~mm} / \mathrm{min}$ and 3000 $\mathrm{mm} / \mathrm{min}$. The time constant for acceleration (and deceleration) is set to $100 \mathrm{~ms}$, which corresponds to an acceleration rate of $0.1 \mathrm{~m} / \mathrm{s}^{2}$ and $0.5 \mathrm{~m} / \mathrm{s}^{2}$ for each feedrate. The measurement distance is $80 \mathrm{~mm}$. The sampling frequency in the experiment is set to 2.5 kHz.

Figure 20 shows the comparison of the measured and computed displacement. The experimental results are filtered using a low-pass filter with a cut-off frequency of 300 $\mathrm{Hz}$, since the vibration in higher frequency is not taken into account in the simulation. The time of the measured result at $600 \mathrm{~mm} / \mathrm{min}$ is adjusted so that the total time is equal to that at $3000 \mathrm{~mm} / \mathrm{min}$. The measured displacement under $600 \mathrm{~mm} / \mathrm{min}$ clearly contains the following components: a variation of about $0.1 \mu \mathrm{m}$ over the measurement time, a periodic fluctuation of a period of $0.2 \mathrm{~s}$ and a fluctuation of higher frequency. The former two variations represent the static straightness error due to geometric inaccuracy of the drive system. The fluctuation of higher frequency can be caused by the variation in motor torque.

Comparing measured displacements at $600 \mathrm{~mm} / \mathrm{min}$ and $3000 \mathrm{~mm} / \mathrm{min}$, about $0.5 \mu \mathrm{m}$ difference is observed from $0 \mathrm{~s}$ to $0.4 \mathrm{~s}$, and another discrepancy of about $0.1 \mu \mathrm{m}$ is 
observed from $1.6 \mathrm{~s}$ to $1.7 \mathrm{~s}$. These are the dynamic path deviation due to the acceleration and deceleration, respectively. The comparison of measured and simulated displacements at $3000 \mathrm{~mm} / \mathrm{min}$ shows that the ACK can reproduce these path deviations. However, the simulated path deviation due to the acceleration is about $0.1 \mu \mathrm{m}$ smaller than the measured profile, and the simulated deviation due to the deceleration is about $0.1 \mu \mathrm{m}$ larger. The reason of these differences is not clear. The static straightness error is not observed in the simulated result, since the straightness error is not taken into account in the simulation.

\section{Conclusion}

The IWF Axis Construction Kit has been compared with commercial FEM software. Required time has been compared in modelling of a machine tool to evaluate the usability of the ACK. In order to investigate the reliability of the ACK, static and dynamic behaviour of both approaches have been compared with each other and with analytical calculations on basic beam models. The behaviour has also been compared with measurements on an actual machine tool. From this study, the following conclusions can be obtained.

(1) The Axis Construction Kit needs $30 \%$ of the total required time for the FEM because of its modularity in machine modelling.

(2) The Axis Construction Kit provides equivalent accuracy to the FEM in basic elastic simulations. The number of degrees of freedom required for the ACK is smaller than that for the FEM.

(3) In static and dynamic simulations on a complete machine, the ACK can obtain equivalent results to the FEM. Almost all lower structural mode shapes and their natural frequencies can be reproduced with the ACK. Dynamic path 
deviations due to acceleration in a straight motion can be reproduced with the ACK.

(4) The elastic body simulation of only crucial parts is sufficient to represent lower structural vibration modes.

\section{Acknowledgement}

The authors like to thank Dr. Johannes Heidenhain GmbH, the Innovation Promotion Agency from the Swiss Confederation, and members of Machining, Measurement and Control laboratory in Kyoto University.

\section{References}

[1] Y. Altintas, C. Brecher, M. Weck and S. Witt: Virtual Machine Tool, Annals of the CIRP, 54, 2(2005), 115.

[2] M.F. Zaeh, Th. Oertli and J. Milberg: Finite Element Modelling of Ball Screw Feed Drive Systems, Annals of the CIRP, 53, 1(2004), 289.

[3] Y. Altintas, Y. Cao: Virtual Design and Optimization of Machine Tool Spindles, Annals of the CIRP, 54, 1(2005), 379.

[4] Y. Cao and Y. Altintas: Modeling of spindle-bearing and machine tool systems for virtual simulation of milling operations, International Journal of Machine Tools \& Manufacture, 47, 9(2007), 1342.

[5] R.R. Craig Jr. and M.C.C. Bampton: Coupling of Substructures for Dynamic Analyses, AIAA Journal, 6, 7(1968), 1313.

[6] R.R. Craig, Jr.: A BRIEF TUTORIAL ON SUBSTRUCTURE ANALYSIS AND TESTING, Proc. SPIE Vol. 4062, Proceedings of IMAC-XVIII: A Conference on Structural Dynamics, 2000, 899. 
[7] G. Bianchi, F. Paolucci, P. Van den Braembusshe, H. Van Brussel and F.Jovane: Towards Virtual Engineering in Machine Tool Design, Annals of the CIRP, 45, 1(1996), 381.

[8] M. Zatarain, E. Lejardi, F. Egana and R. Bueno: Modular Synthesis of Machine Tools, Annals of the CIRP, 47, 1(1998), 333.

[9] B. Zettl, W. Szyszkowski and W.J. Zhang: Accurate low DOF modeling of a planar compliant mechanism with flexure hinges: the equivalent beam methodology, Precision Engineering, 29, 2(2005), 237.

[10] J.W.M.C. Teeuwsen, J.A. Soons, P.H.J. Schellekens and A.C.H. van der Wolf: A General Method for Error Description of CMMs Using Polynomial Fitting Procedures, Annals of the CIRP, 38, 1(1989), 505.

[11] F. Rehsteiner, S. Weikert and Z. Rak: Accuracy Optimization of Machine Tools under Acceleration Loads for the Demands of High-Speed-Machining, Proceedings of the ASPE 1998 Annual Meeting, St. Louis, Mis., Oct, 602.

[12] M. Weck and B. Mueller-Held: Virtuelle Produkt-und Prozessentwicklung, WT Werkstattstechnik online 90 H.7/8, Springer-VDI-Verlag, 2000, 302.

[13] G. Pritschow, G. Rogers and S. Roeck: Echtzeitfaehige Maschinenmodelle, WT Werkstattstechnik online 92 H.5, Springer-VDI-Verlag, 2002, 187.

[14] M. Zeah and D.Siedl: A New Method for Simulation of Machining Performance by Integrating Finite Element and Multi-body Simulation for Machine Tools, Annals of the CIRP, 56, 1(2007), 383.

[15] G. Pritschow and N. Croon: Wege zur virtuellen Werkzeugmaschine, WT Werkstattstechnik online 92 H.5, Springer-VDI-Verlag, 2002, 194 
[16] Th. Lorenzer, S.Weikert, S. Bossoni and K. Wegener: Modeling and evaluation tool for supporting decisions on the design of reconfigurable machine tools, Journal of Manufacturing Systems, 26, 3-4(2007), 167 


\section{List of Figure Captions}

Figure 1 Appearance of the machine under investigation

Figure 2 Simulation model developed with the ACK

Figure 3 Five different models used in simulations

Figure 4 Comparison of required time with the ACK and a commercial FEM

Figure 5 Cantilever used in the calculation

Figure 6 Relationship between nDOF and deviation from the analytical displacement for a cantilever with the ACK

Figure 7 Relationship between $\mathrm{nDOF}$ and deviation from the analytical displacement for a cantilever with the FEM

Figure 8 Relationship between $\mathrm{nDOF}$ and deviation from the analytical natural frequency for a cantilever with the ACK

Figure 9 Relationship between $\mathrm{nDOF}$ and deviation from the analytical natural frequency for a cantilever with the FEM

Figure 10 Beam, fixed on both sides, used in the calculation

Figure 11 Relationship between $\mathrm{nDOF}$ and deviation from the analytical displacement for the fixed beam of Fig. 10 with the ACK

Figure 12 Relationship between $\mathrm{nDOF}$ and deviation from the analytical displacement for the fixed beam of Fig. 10 with the FEM

Figure 13 Relationship between $\mathrm{nDOF}$ and deviation from the analytical natural frequency for the fixed beam of Fig.10 with the ACK

Figure 14 Relationship between $\mathrm{nDOF}$ and deviation from the analytical natural frequency for the fixed beam of Fig.10 with the FEM

Figure 15 Experimental setup for compliance measurement 
Figure 16 Relationship between the measured displacement and force applied

Figure 17 Relationship between elasticity and deviation from the experimental compliance with the ACK

Figure 18 Relationship between elasticity and deviation from the experimental compliance with the FEM

Figure 19 Examples of mode shapes obtained by experimental modal analysis

(a) Mode 1 at $80 \mathrm{~Hz}$

(b) Mode 4 at $163 \mathrm{~Hz}$

Figure 20 Comparison of measured and simulated displacement of TCP 


\section{List of Table Captions}

Table 1 Major specifications of the machine tool and the vibration isolation table

Table 2 Natural frequencies and mode shapes obtained by experimental modal analysis

Table 3 Natural frequencies of the machine calculated with the ACK and the FEM.

"Comp. with exp." stands for "comparison with experiment". 
Table 1 Major specifications of the machine tool and the vibration isolation table

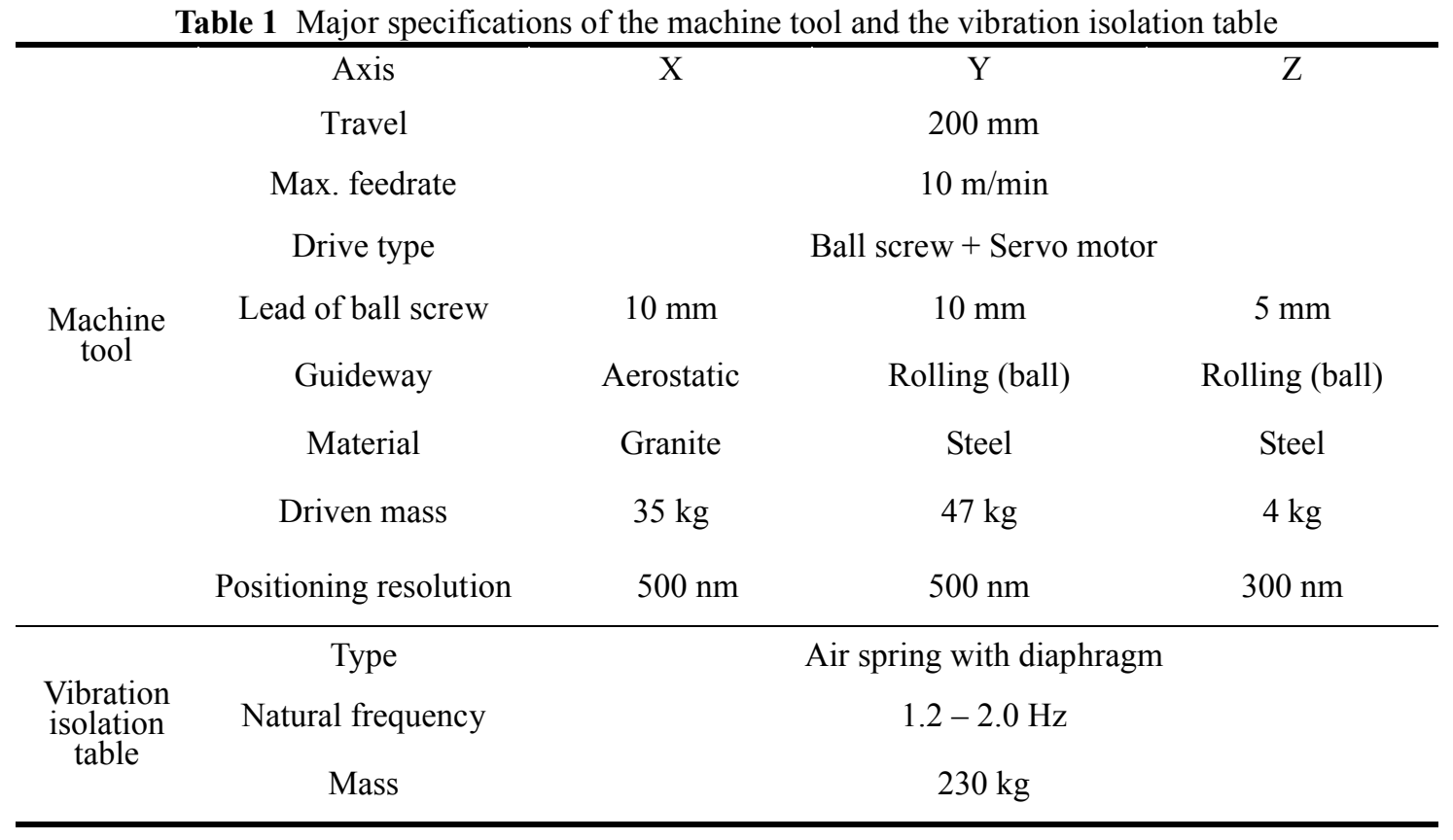


Table2 Natural frequencies and mode shapes obtained by experimental modal analysis

\begin{tabular}{|c|c|c|}
\hline $\begin{array}{l}\text { Mode } \\
\text { order }\end{array}$ & $\begin{array}{l}\text { Natural } \\
\text { frequency } \mathrm{Hz}\end{array}$ & Description of dominant mode shapes \\
\hline 1 & 80 & $\begin{array}{l}\text { (1) B-rotation of Y-base, Y-slider and Z-slider caused by the deformation of columns } \\
\text { (2) B-rotation of Machine base and X-slider in the counter phase to (1) }\end{array}$ \\
\hline 2 & 141 & $\begin{array}{l}\text { (1) C-rotation of Y-base, Y-slider and Z-slider caused by the deformation of columns } \\
\text { (2) C-rotation of X-slider in the counter phase to (1) }\end{array}$ \\
\hline 3 & 154 & $\begin{array}{l}\text { (1) C-rotation of Y-base, Y-slider and Z-slider caused by the deformation of columns } \\
\text { (2) C-rotation of X-slider in the simultaneous phase to (1) }\end{array}$ \\
\hline 4 & 163 & $\begin{array}{l}\text { (1) B-rotation of Y-slider and Z-slider caused by the deformation of Y-base } \\
\text { (2) X-translation of Machine base and X-slider }\end{array}$ \\
\hline 5 & 180 & $\begin{array}{l}\text { (1) B-rotation of Y-slider and Z-slider caused by the deformation of Y-base and columns } \\
\text { (2) Y-translation of Y-base, Y-slider and Z-slider } \\
\text { (3) X-translation and B-rotation of Machine base and X-slider } \\
\text { (4) Y-translation and A-rotation of Machine base and X-slider in the counter phase to (2) }\end{array}$ \\
\hline 6 & 203 & $\begin{array}{l}\text { (1) B-rotation of Y-slider and Z-slider caused by the deformation of Y-base and columns } \\
\text { (2) A-rotation of Y-slider and Z-slider } \\
\text { (3) X-translation and B-rotation of Machine base and X-slider in the simultaneous phase to (1) }\end{array}$ \\
\hline 7 & 236 & $\begin{array}{l}\text { (1) B-rotation of Y-slider and Z-slider caused by the deformation of Y-base and columns } \\
\text { (2) A-rotation of Y-slider and Z-slider in the counter phase to (2) in the mode } 6 \\
\text { (3) X-translation and B-rotation of Machine base and X-slider in the counter phase to (1) }\end{array}$ \\
\hline 8 & 261 & $\begin{array}{l}\text { (1) A-rotation of Y-slider and Z-slider } \\
\text { (2) Y-translation of X-slider } \\
\text { (3) Y-translation of Y-base in the counter phase of (2) }\end{array}$ \\
\hline 9 & 274 & $\begin{array}{l}\text { (1) A-rotation of Y-slider and Z-slider } \\
\text { (2) Y-translation of Y-slider and Z-slider } \\
\text { (3) Y-translation of X-slider in the simultaneous phase of (2) } \\
\text { (4) Y-translation of Y-base in the counter phase of (2) }\end{array}$ \\
\hline
\end{tabular}


Table 3 Natural frequencies of the machine calculated with the ACK and the FEM "Comp. with exp." stands for "comparison with experiment".

\begin{tabular}{|c|c|c|c|c|c|c|c|c|c|c|}
\hline \multirow{2}{*}{$\begin{array}{l}\text { Mode } \\
\text { order }\end{array}$} & \multicolumn{2}{|c|}{$\mathrm{R}$ with ACK } & \multicolumn{2}{|c|}{ BE with ACK } & \multicolumn{2}{|c|}{ CE with ACK } & \multicolumn{2}{|c|}{ YCE with ACK } & \multicolumn{2}{|c|}{ YCE with FEM } \\
\hline & $\begin{array}{l}\text { Natural } \\
\text { Freq. } \mathrm{Hz}\end{array}$ & $\begin{array}{l}\text { Comp. } \\
\text { with exp. }\end{array}$ & $\begin{array}{l}\text { Natural } \\
\text { Freq. } \mathrm{Hz}\end{array}$ & $\begin{array}{l}\text { Comp. } \\
\text { with exp. }\end{array}$ & $\begin{array}{l}\text { Natural } \\
\text { Freq. } \mathrm{Hz}\end{array}$ & $\begin{array}{l}\text { Comp. } \\
\text { with exp. }\end{array}$ & $\begin{array}{l}\text { Natural } \\
\text { Freq. } \mathrm{Hz}\end{array}$ & $\begin{array}{l}\text { Comp. } \\
\text { with exp. }\end{array}$ & $\begin{array}{l}\text { Natural } \\
\text { Freq. } \mathrm{Hz}\end{array}$ & $\begin{array}{l}\text { Comp. } \\
\text { with exp. }\end{array}$ \\
\hline 1 & 146 & & 78.6 & $\begin{array}{l}\text { Mode } 1 \\
80 \mathrm{~Hz}\end{array}$ & 84.5 & $\begin{array}{ll}\text { Mode } 1 \\
80 \quad \mathrm{~Hz} \\
\end{array}$ & 76.9 & $\begin{array}{l}\text { Mode } 1 \\
80 \mathrm{~Hz}\end{array}$ & 78.2 & $\begin{array}{l}\text { Mode } 1 \\
80 \mathrm{~Hz}\end{array}$ \\
\hline 2 & 233 & & 146 & & 145 & & 143 & $\begin{array}{l}\text { Mode } 2 \\
141 \mathrm{~Hz}\end{array}$ & 144 & $\begin{array}{l}\text { Mode } 2 \\
141 \mathrm{~Hz}\end{array}$ \\
\hline 3 & 254 & $\begin{array}{l}\text { Mode8 } \\
261 \mathrm{~Hz}\end{array}$ & 239 & $\begin{array}{l}\text { Mode } 4 \\
163 \mathrm{~Hz}\end{array}$ & 225 & $\begin{array}{l}\text { Mode } 3 \\
154 \mathrm{~Hz}\end{array}$ & 150 & $\begin{array}{l}\text { Mode } 3 \\
154 \mathrm{~Hz}\end{array}$ & 153 & $\begin{array}{l}\text { Mode } 3 \\
154 \mathrm{~Hz}\end{array}$ \\
\hline 4 & 302 & $\begin{array}{l}\text { Mode9 } \\
274 \mathrm{~Hz}\end{array}$ & 249 & $\begin{array}{l}\text { Mode } 8 \\
261 \mathrm{~Hz} \\
\end{array}$ & 236 & $\begin{array}{l}\text { Mode } 4 \\
163 \mathrm{~Hz} \\
\end{array}$ & 160 & $\begin{array}{l}\text { Mode } 4 \\
163 \mathrm{~Hz} \\
\end{array}$ & 172 & $\begin{array}{l}\text { Mode } 4 \\
163 \mathrm{~Hz} \\
\end{array}$ \\
\hline 5 & & & 288 & $\begin{array}{l}\text { Mode } 9 \\
274 \mathrm{~Hz}\end{array}$ & 254 & $\begin{array}{l}\text { Mode } 8 \\
261 \mathrm{~Hz}\end{array}$ & 237 & $\begin{array}{l}\text { Mode } 6 \\
203 \mathrm{~Hz}\end{array}$ & 237 & $\begin{array}{l}\text { Mode } 6 \\
203 \mathrm{~Hz}\end{array}$ \\
\hline 6 & & & & & 297 & & 247 & $\begin{array}{l}\text { Mode } 8 \\
261 \mathrm{~Hz}\end{array}$ & 250 & $\begin{array}{l}\text { Mode } 8 \\
261 \mathrm{~Hz} \\
\end{array}$ \\
\hline 7 & & & & & & & 272 & $\begin{array}{l}\text { Mode } 9 \\
274 \mathrm{~Hz}\end{array}$ & 276 & $\begin{array}{l}\text { Mode } 9 \\
274 \mathrm{~Hz}\end{array}$ \\
\hline
\end{tabular}




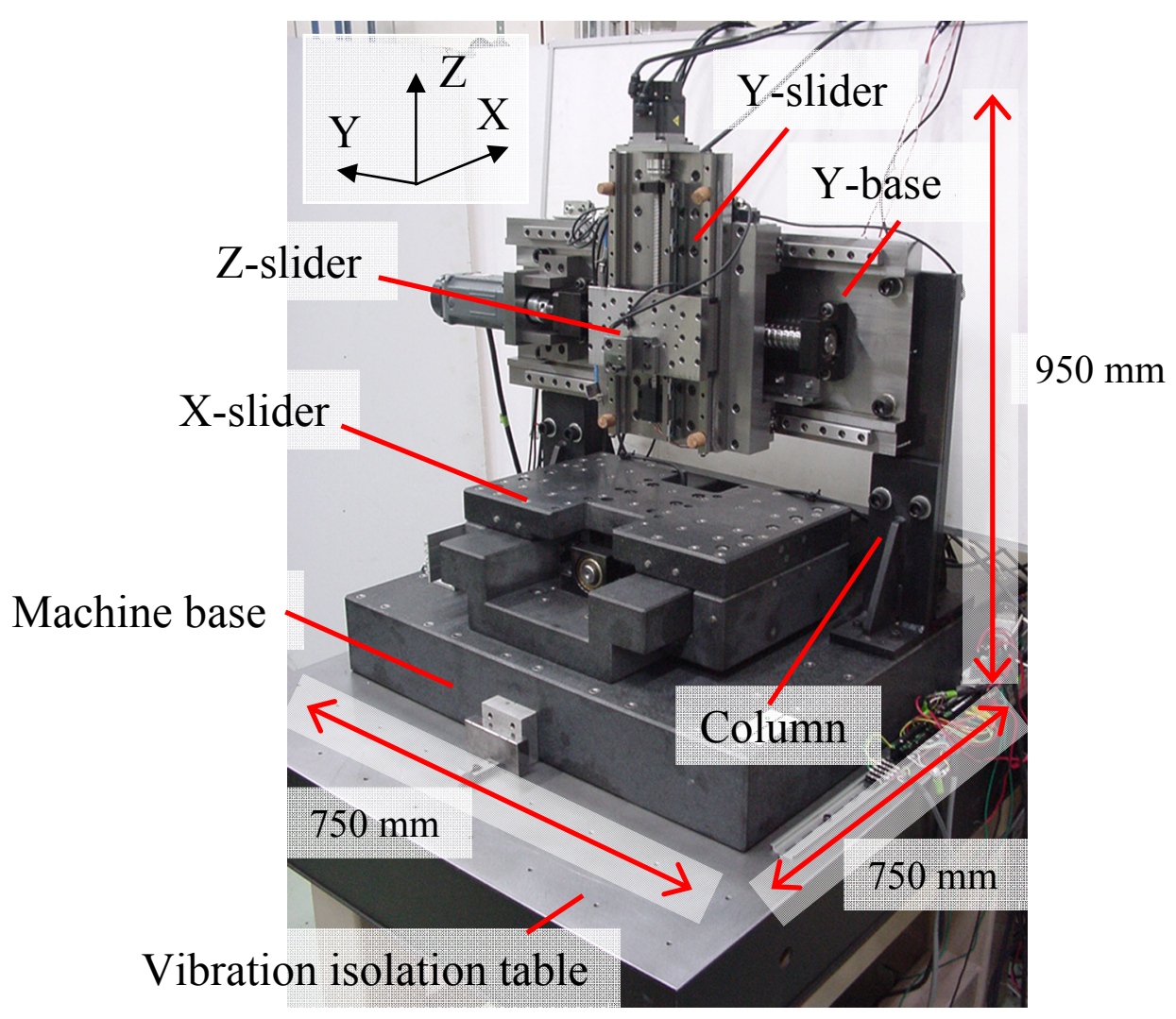




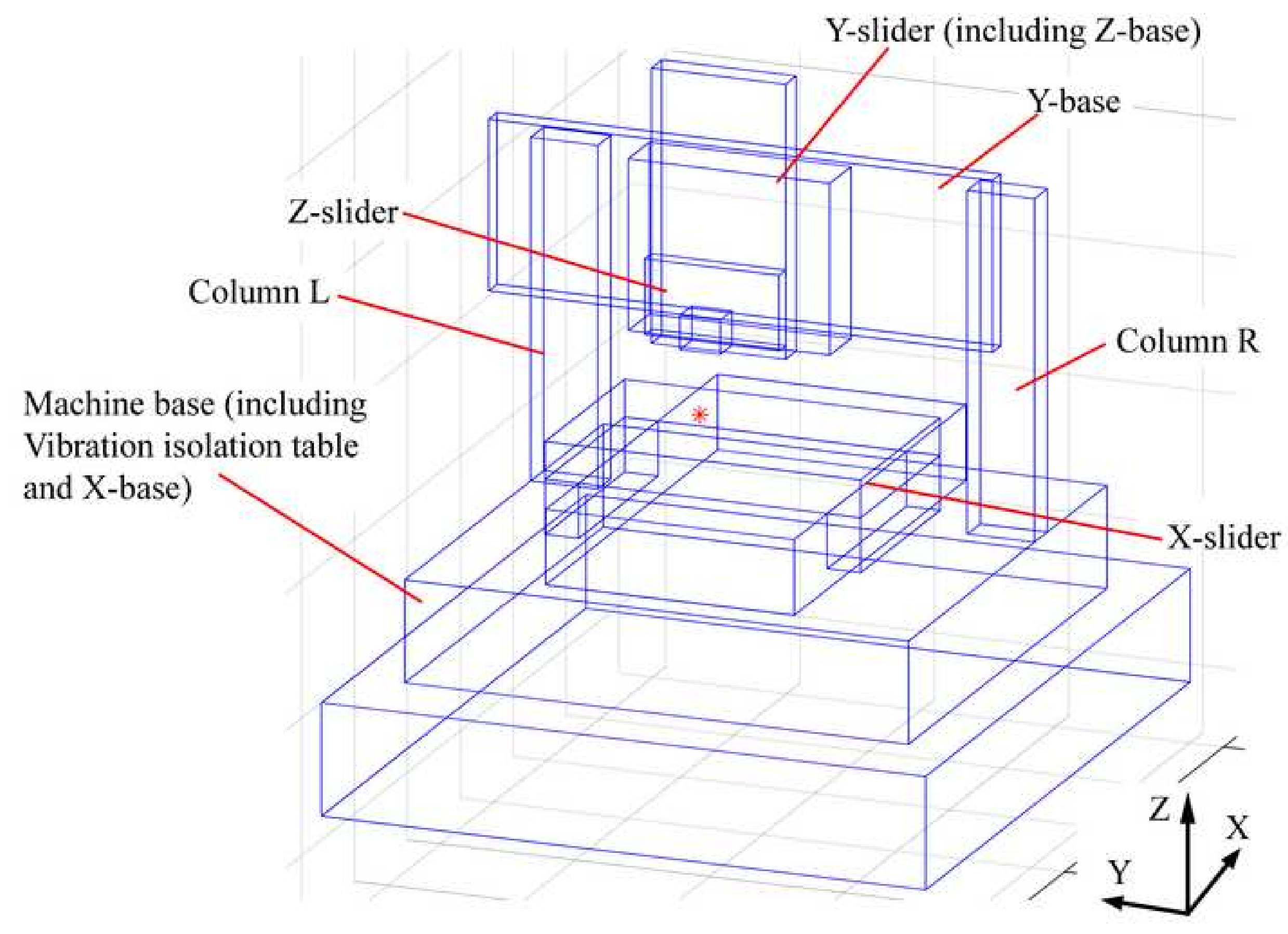

Machine base (including Vibration isolation table and X-base) 


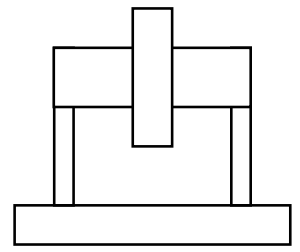

Rigid (R)

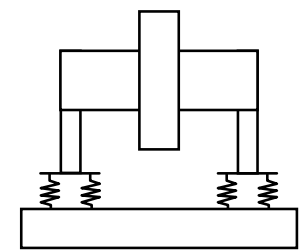

Bolts elastic (BE)

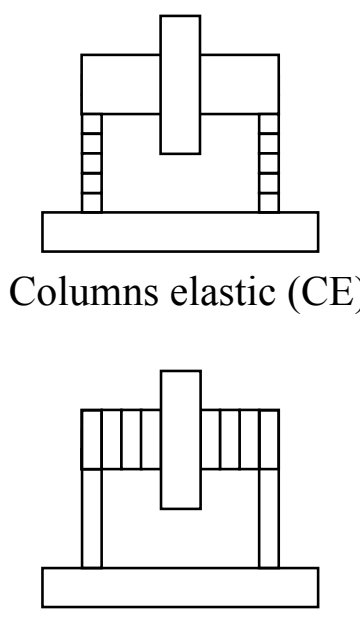

Y-base elastic (YE)

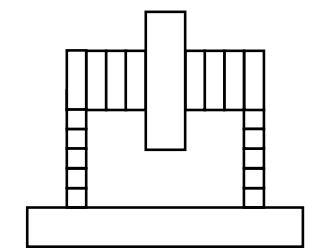

Y-base and columns elastic (YCE)

Rigid Elastic 


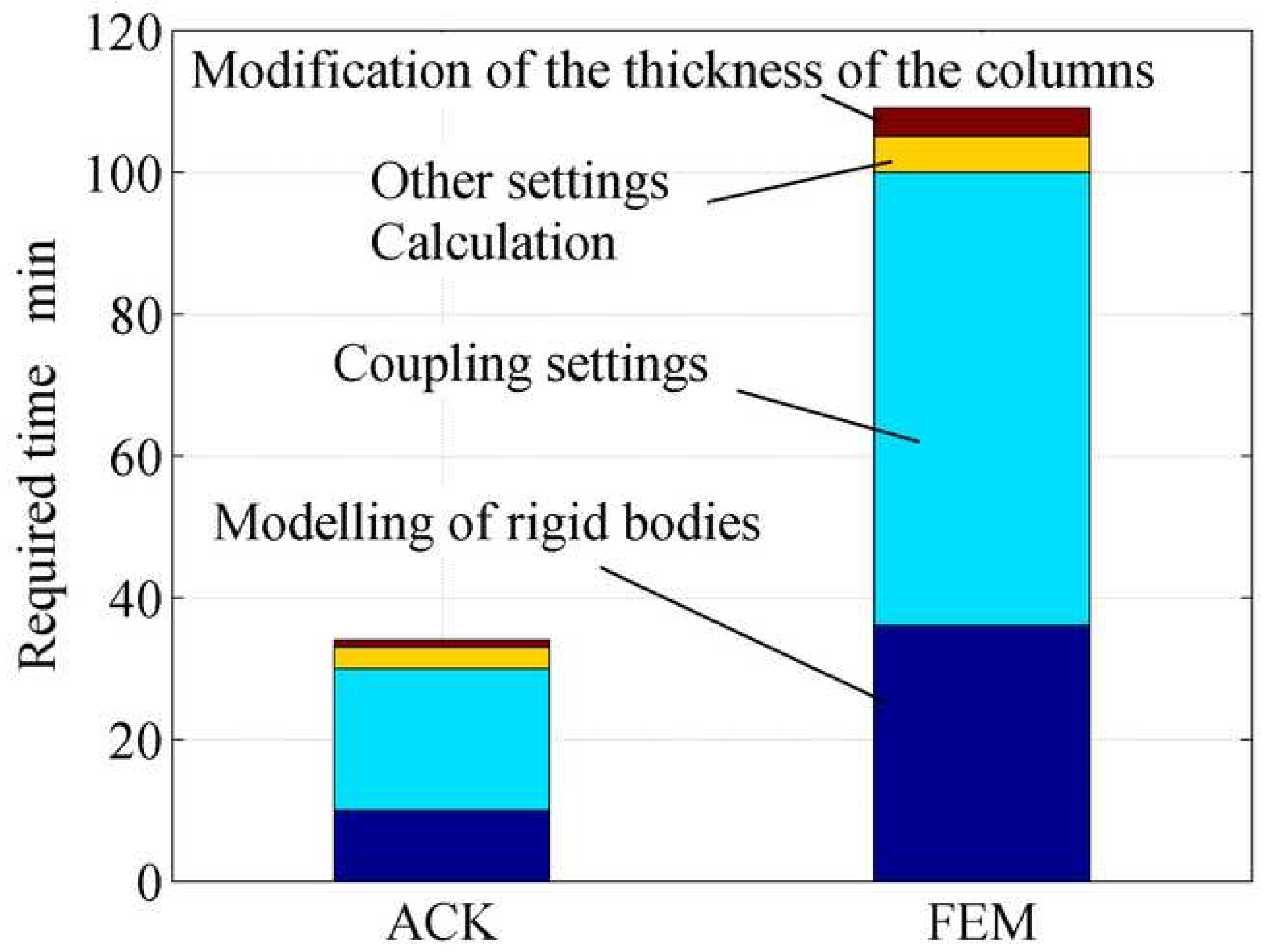




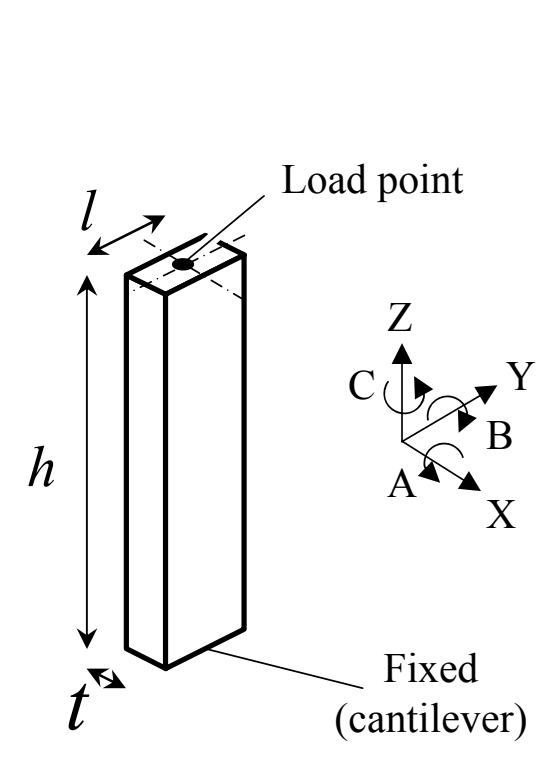

\section{列}




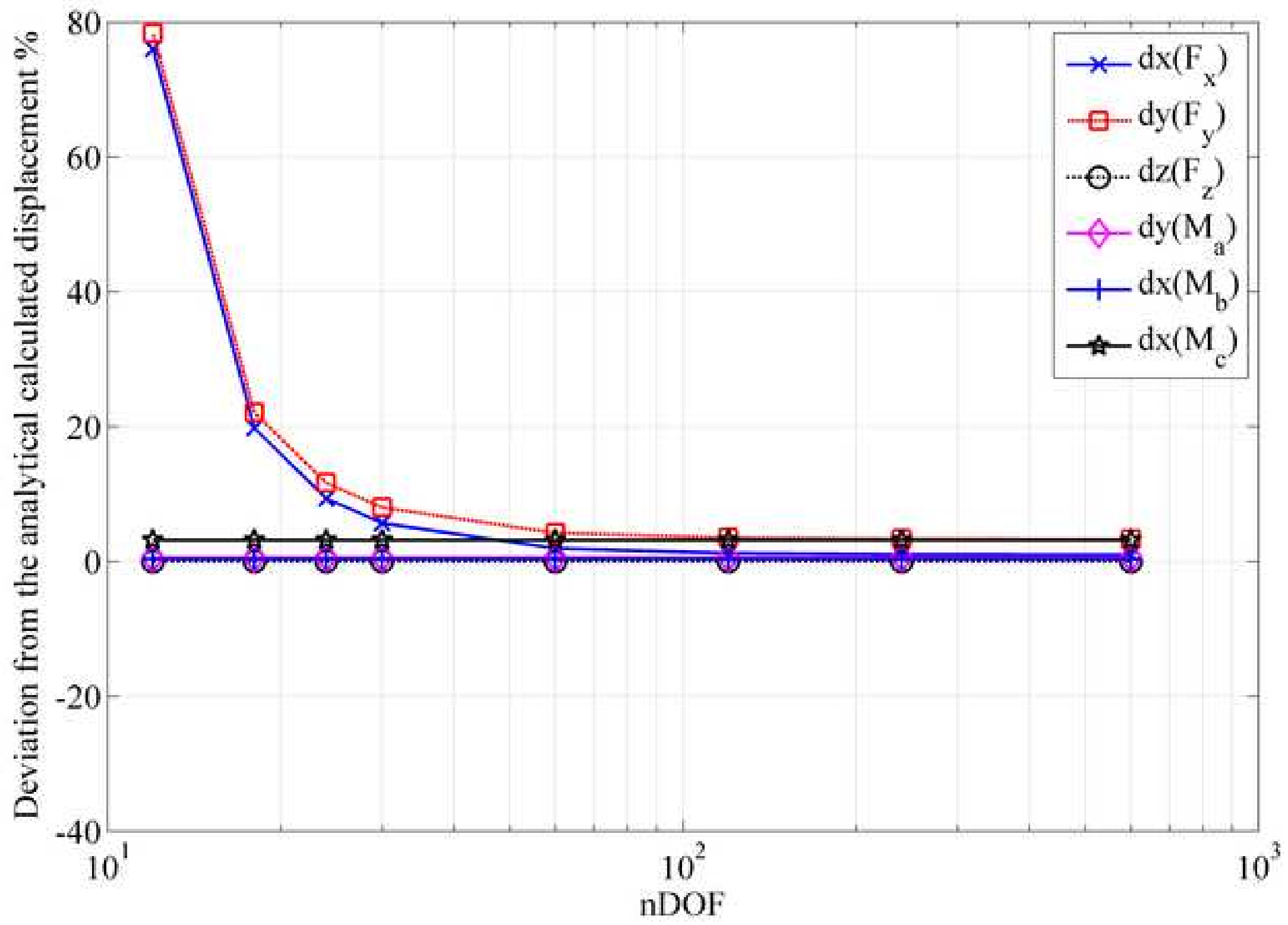


Click here to download high resolution image

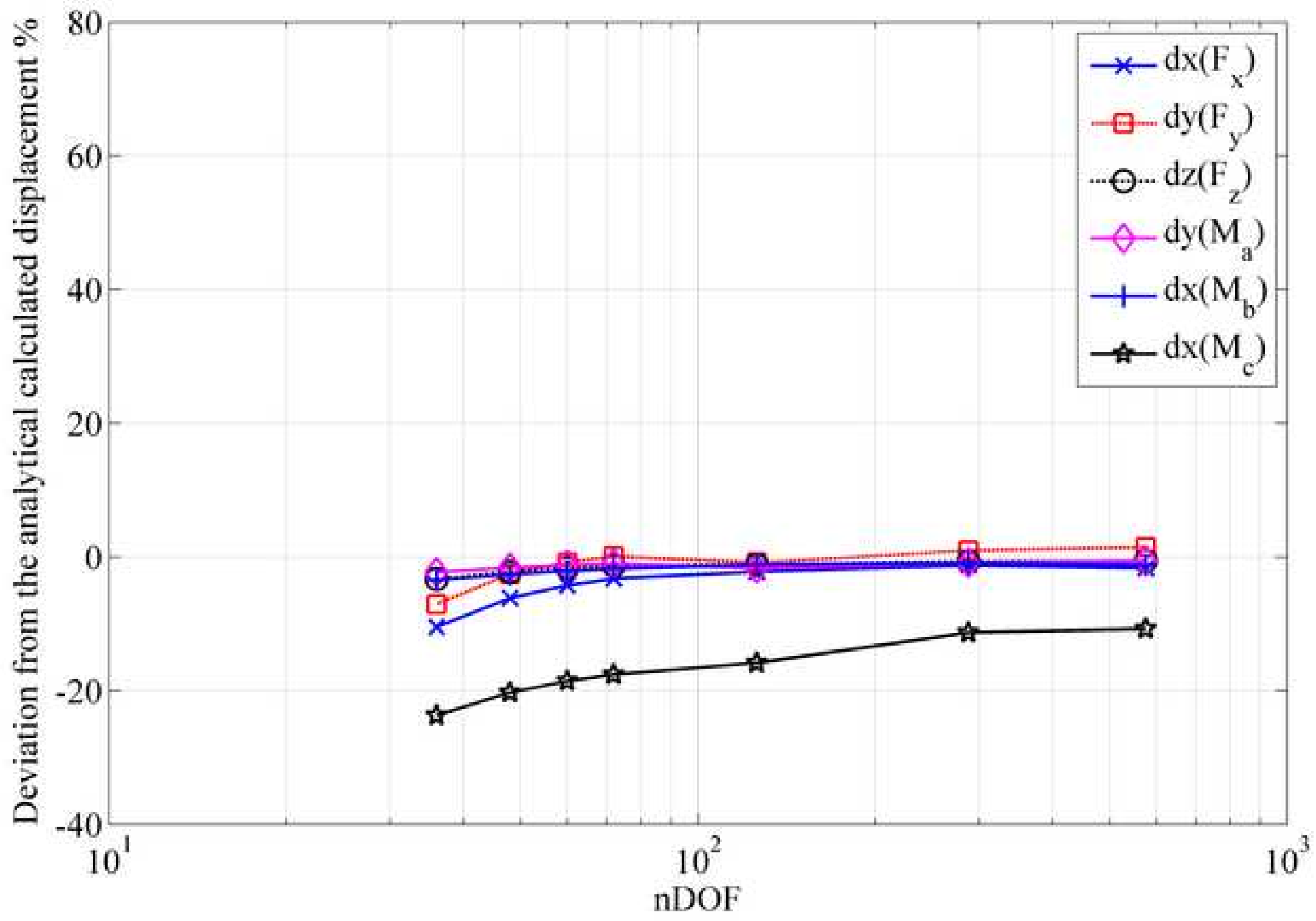




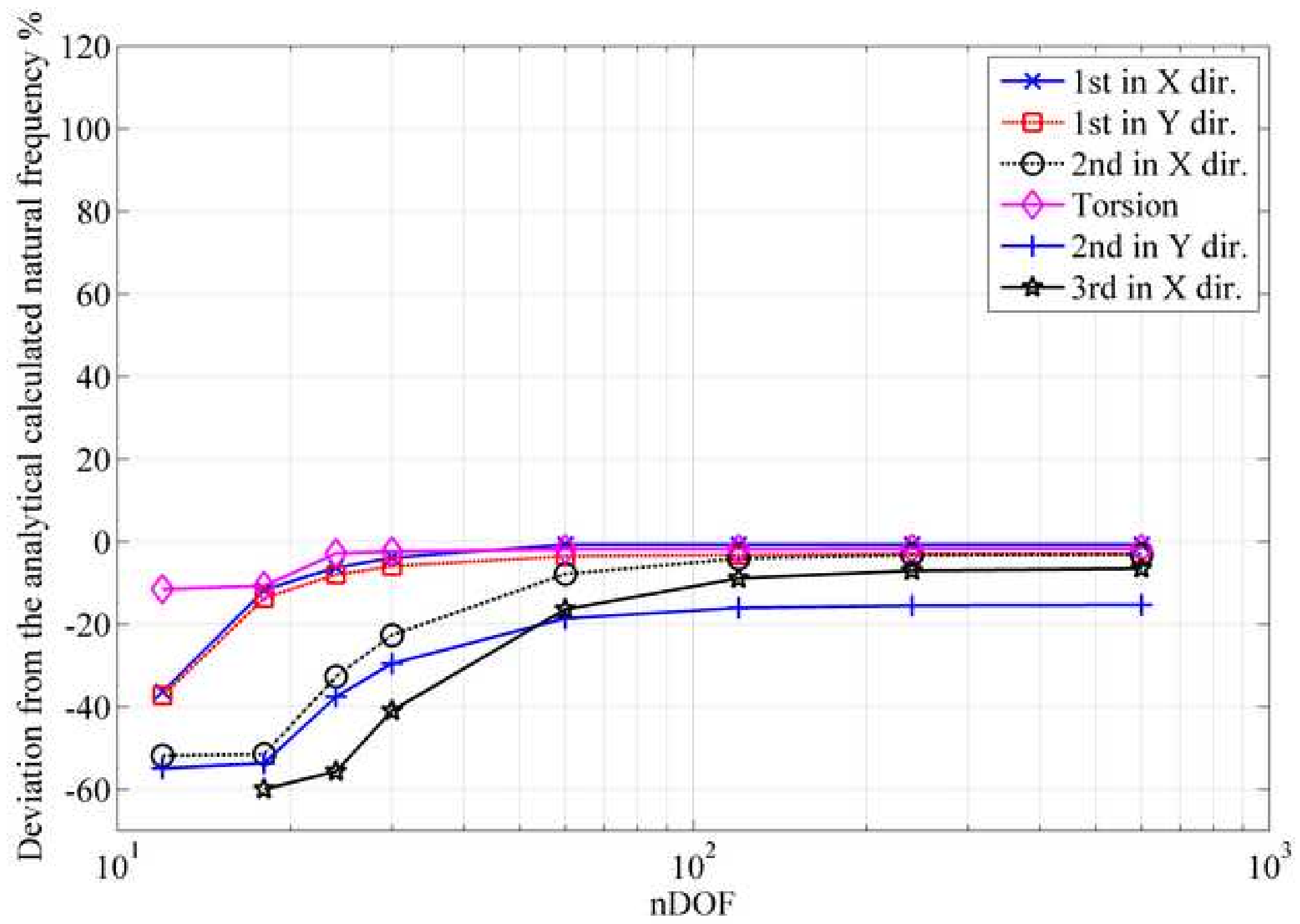




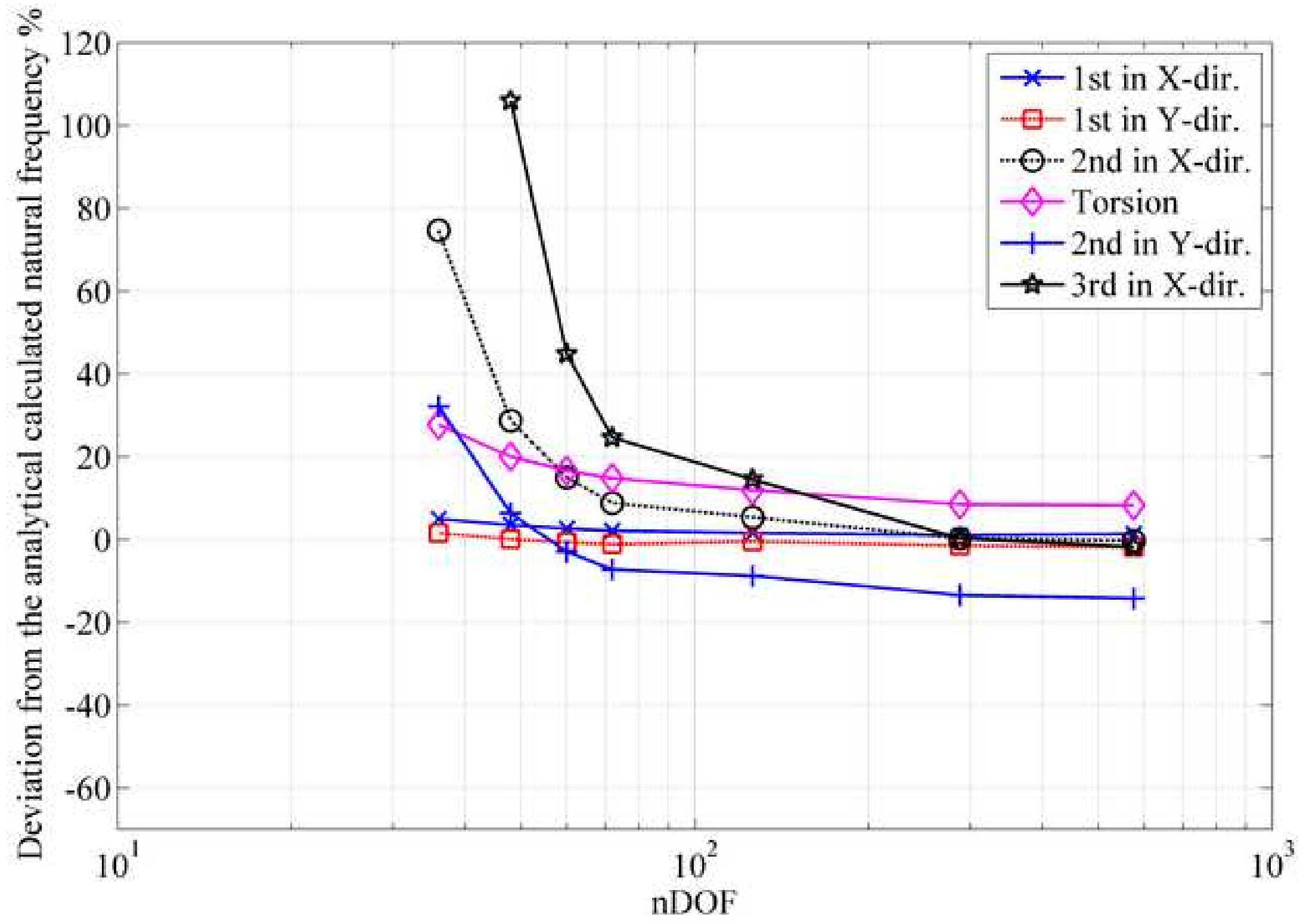




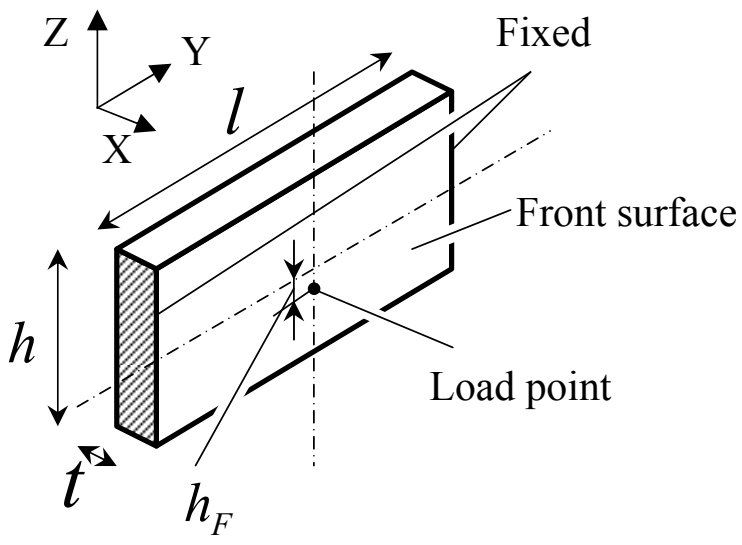


Click here to download high resolution image

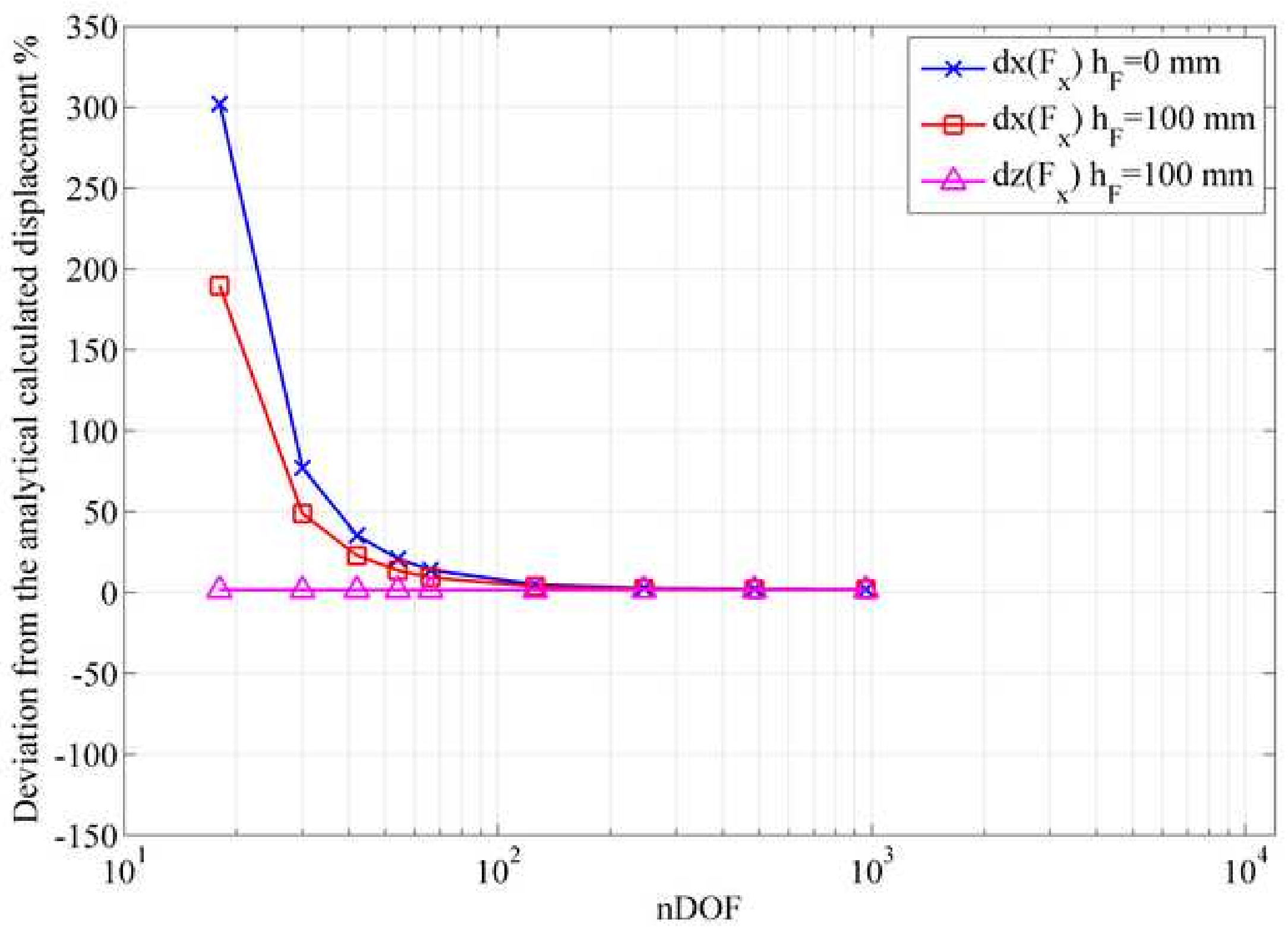




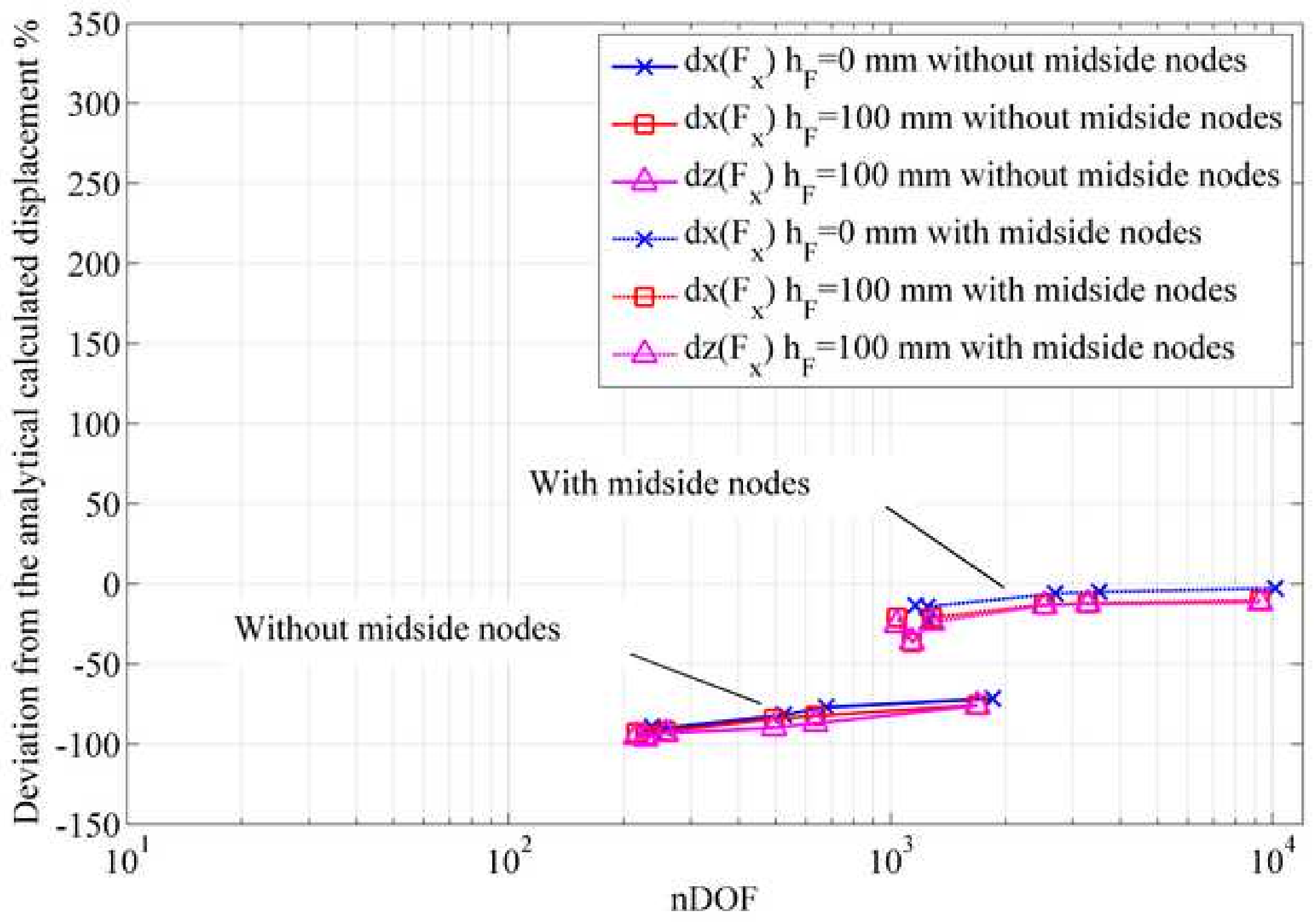


Click here to download high resolution image

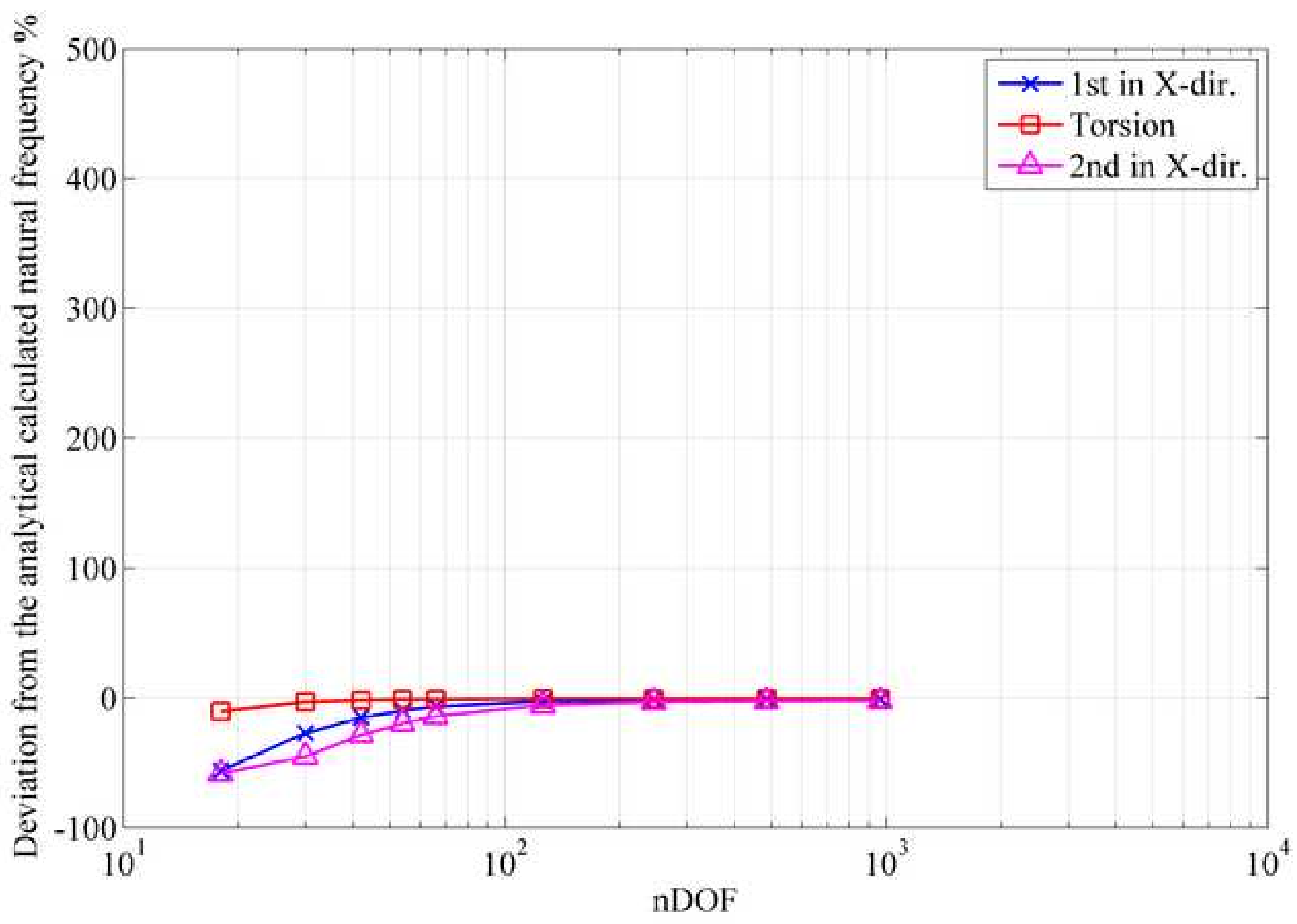


Click here to download high resolution image

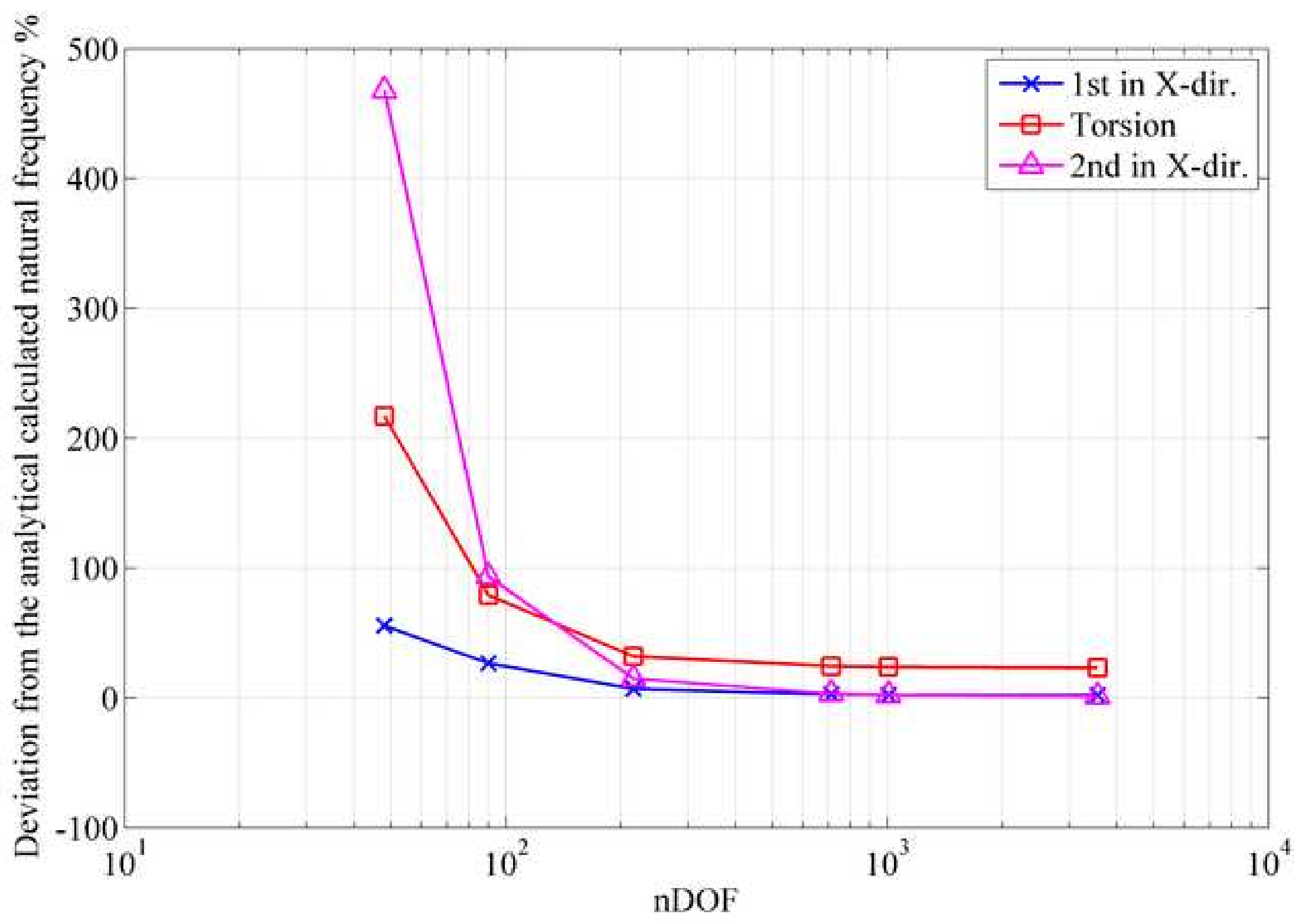




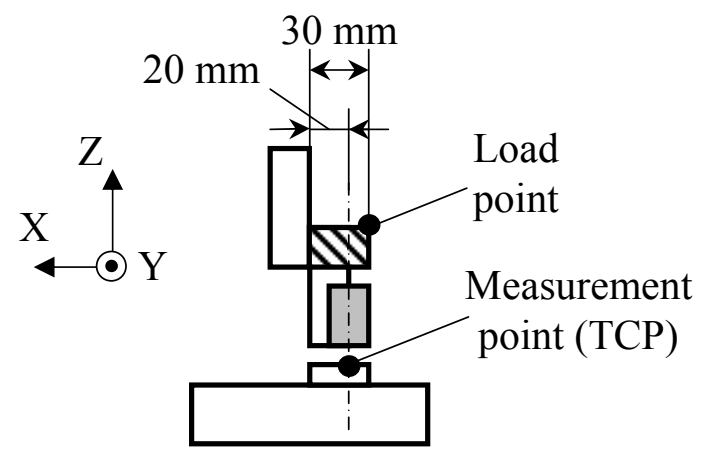

(a) Left side view

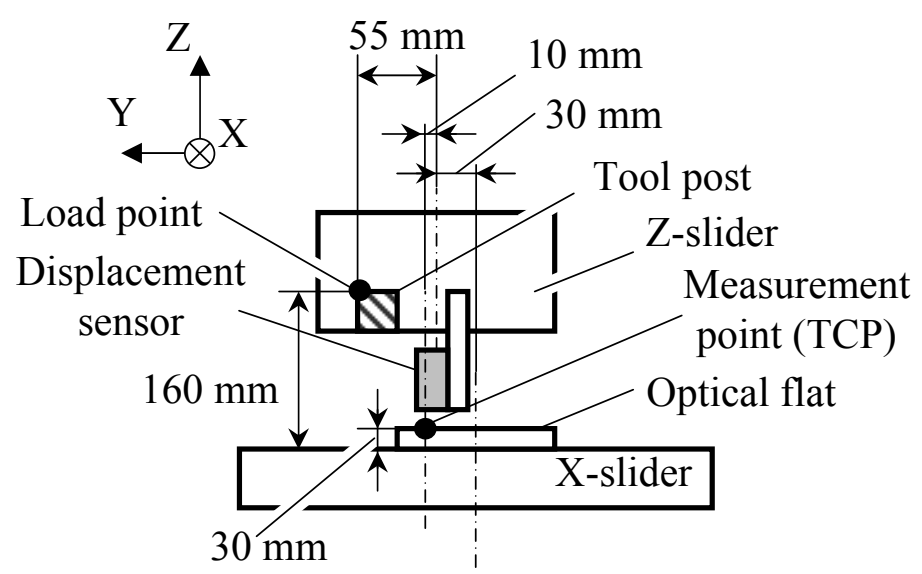

(b) Front view 


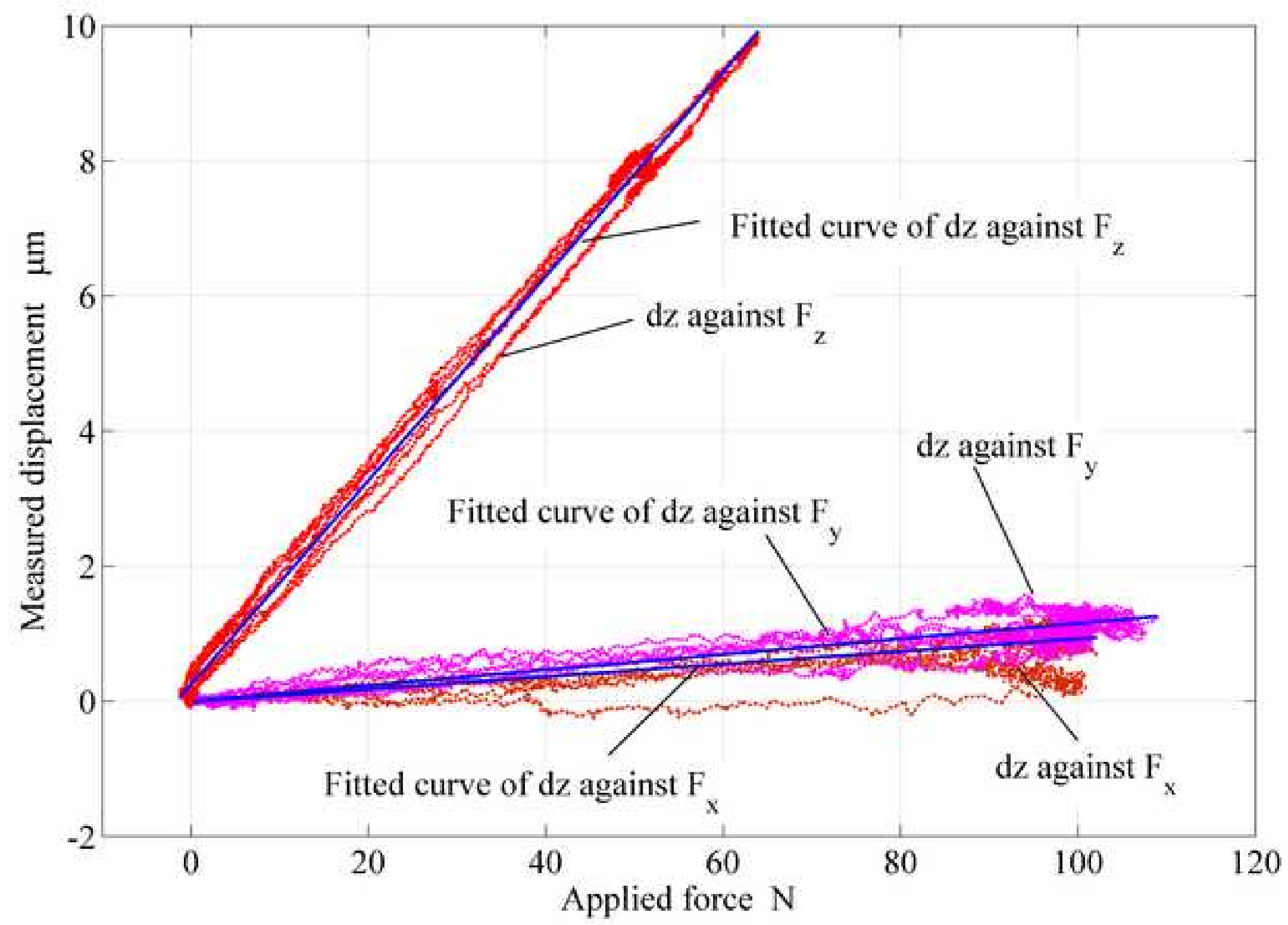




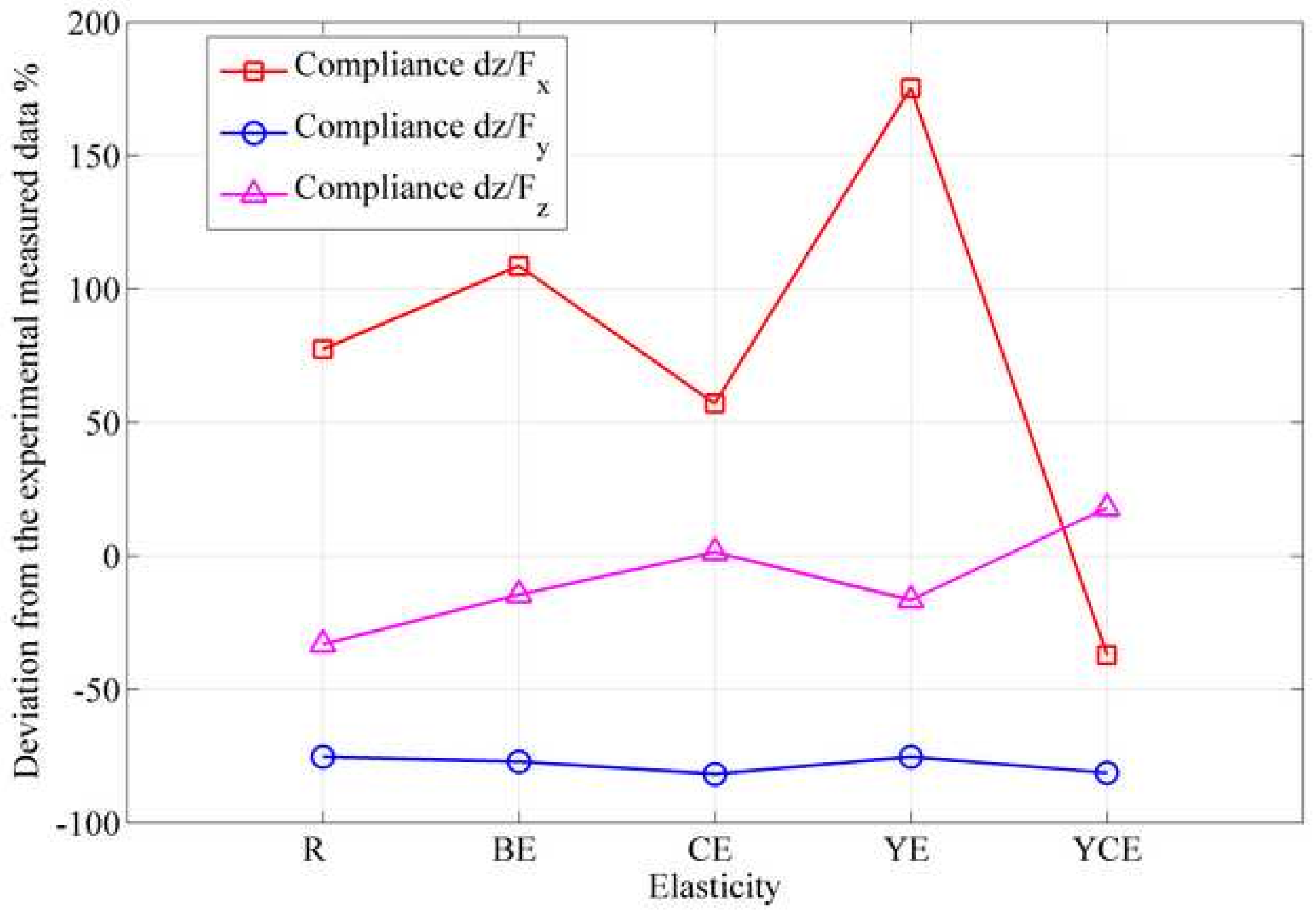


Click here to download high resolution image

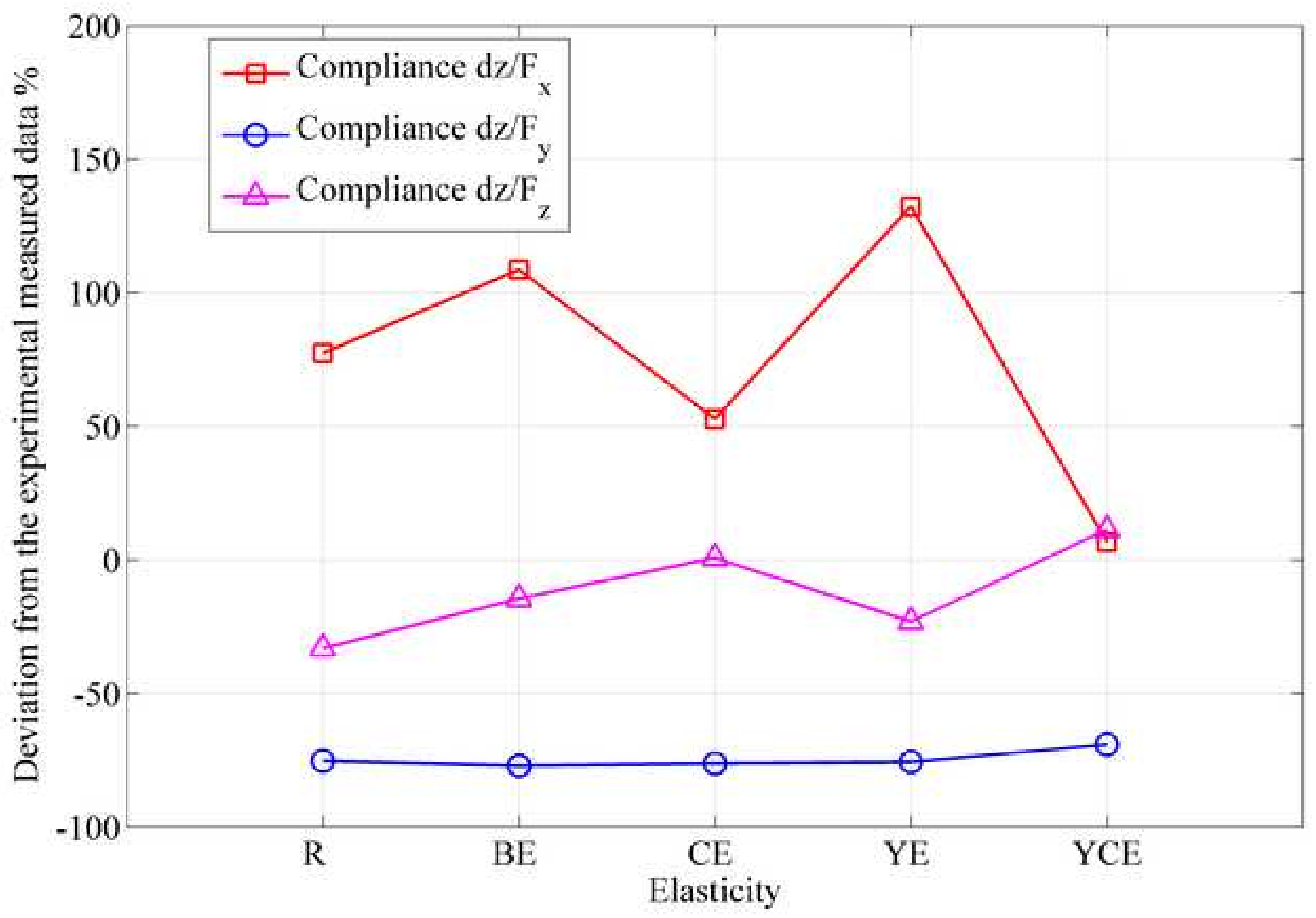


Figure 19a

Click here to download high resolution image

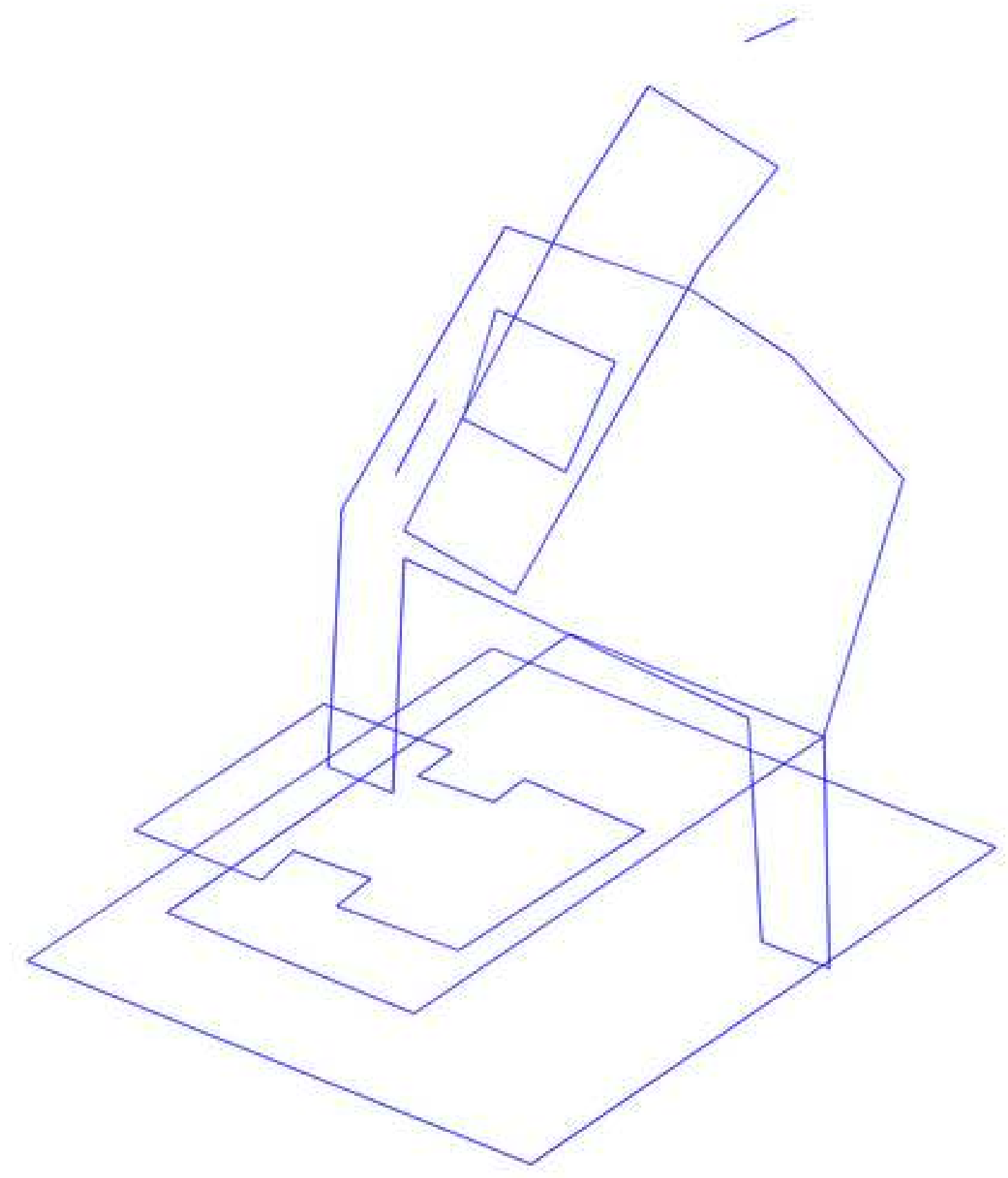




\section{Figure 19b}

Click here to download high resolution image

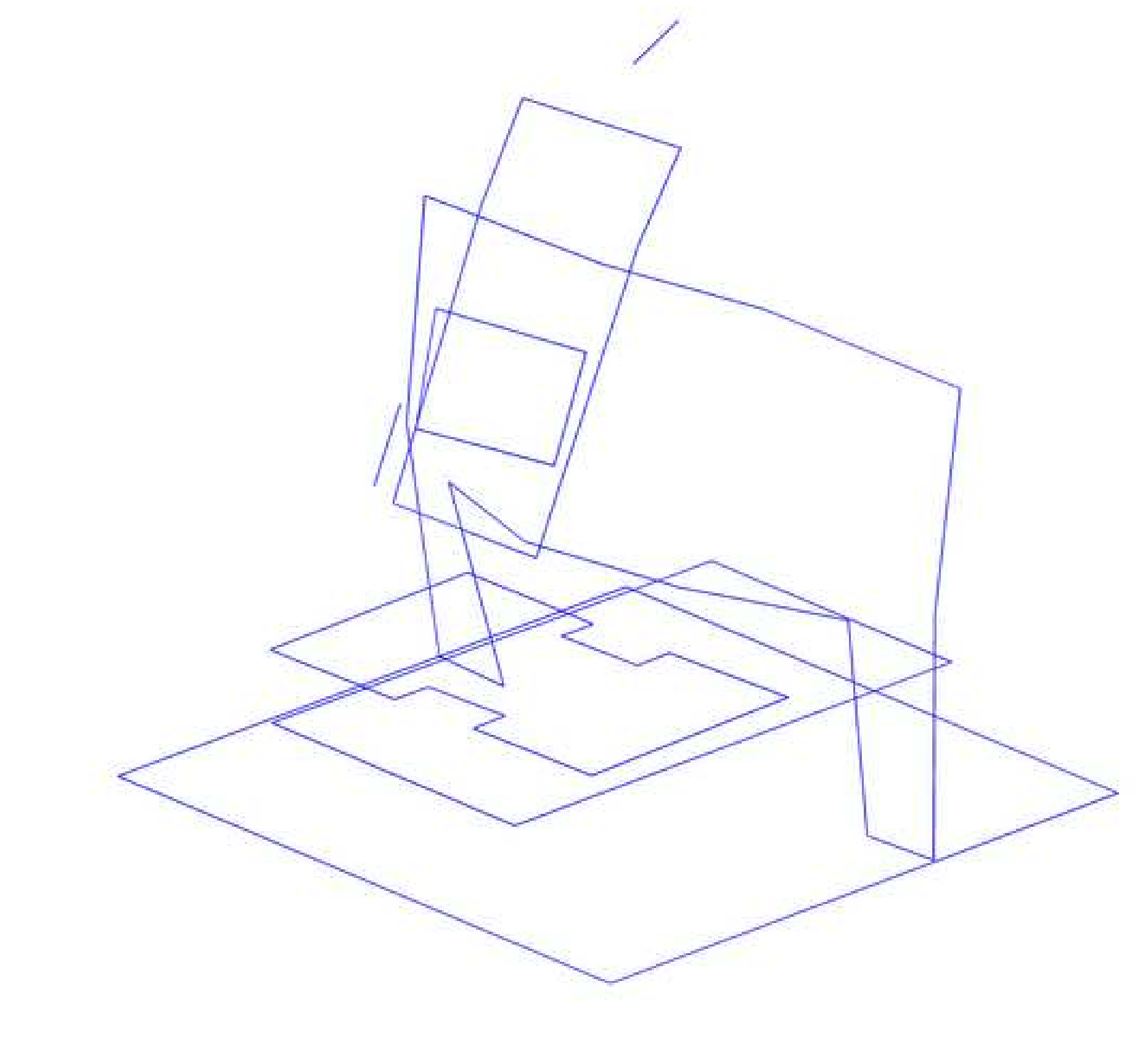

列

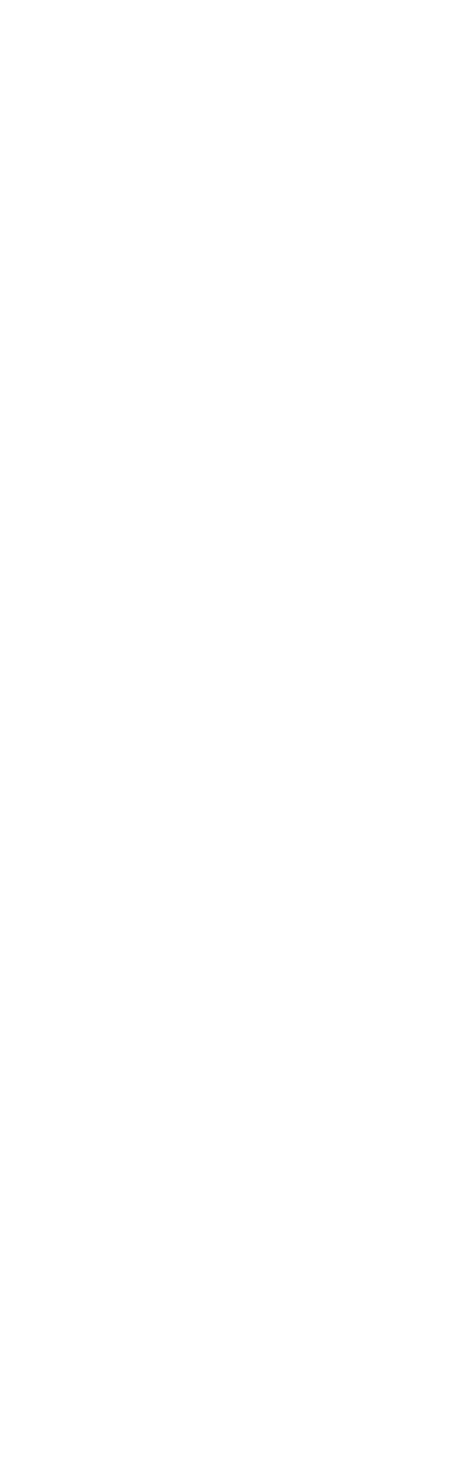




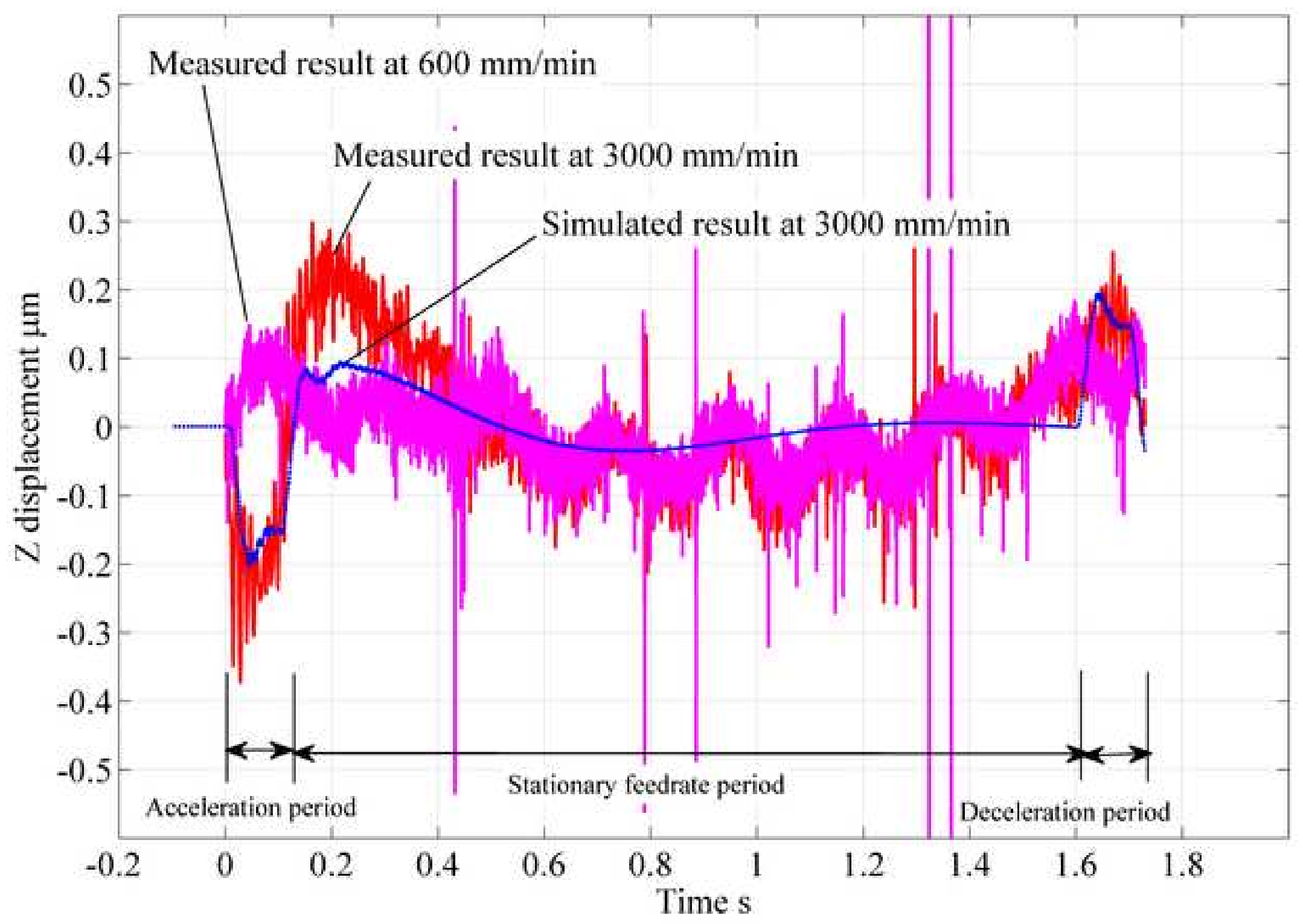

